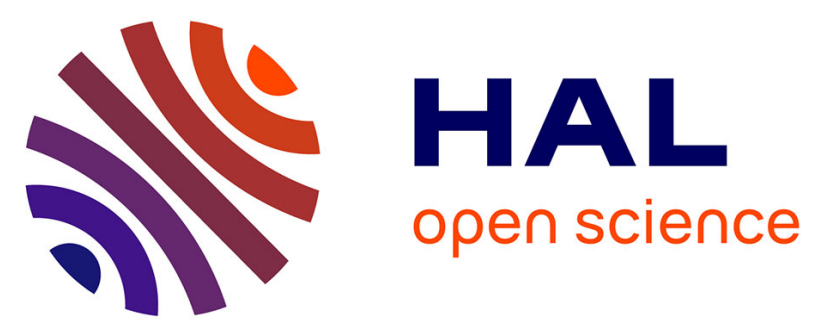

\title{
In the mouse, prostaglandin D2 signalling protects the endometrium against adenomyosis
}

\author{
Pascal Philibert, Stéphanie Déjardin, Nelly Pirot, Alain Pruvost, Anvi
}

Laetitia Nguyen, Florence Bernex, Francis Poulat, Brigitte Boizet-Bonhoure

\section{- To cite this version:}

Pascal Philibert, Stéphanie Déjardin, Nelly Pirot, Alain Pruvost, Anvi Laetitia Nguyen, et al.. In the mouse, prostaglandin D2 signalling protects the endometrium against adenomyosis. Molecular Human Reproduction, 2021, 27 (5), 10.1093/molehr/gaab029 . hal-03436852

\section{HAL Id: hal-03436852 https://hal.science/hal-03436852}

Submitted on 19 Nov 2021

HAL is a multi-disciplinary open access archive for the deposit and dissemination of scientific research documents, whether they are published or not. The documents may come from teaching and research institutions in France or abroad, or from public or private research centers.
L'archive ouverte pluridisciplinaire HAL, est destinée au dépôt et à la diffusion de documents scientifiques de niveau recherche, publiés ou non, émanant des établissements d'enseignement et de recherche français ou étrangers, des laboratoires publics ou privés. 


\section{In the mouse, prostaglandin D2 signalling protects the}

\section{endometrium against adenomyosis}

Running title : Prostaglandin D2 inhibits uterine adenomyosis

Pascal Philibert ${ }^{1,2}$, Stéphanie Déjardin ${ }^{1}$, Nelly Pirot ${ }^{3,4}$, Alain Pruvost ${ }^{5}$, Anvi

Laetitia Nguyen ${ }^{5}$, Florence Bernex ${ }^{3,4}$, Francis Poulat ${ }^{1}$ and Brigitte Boizet-

Bonhoure $^{1^{*}}$

${ }^{1}$ Institut de Génétique Humaine, Centre National de la Recherche Scientifique, Université de

Montpellier, 34396 Montpellier, France ${ }^{2}$ Laboratoire de Biochimie et Biologie Moléculaire,

Hôpital Carèmeau, CHU de Nîmes, 30029 Nîmes, France ${ }^{3}$ Institut de Recherche en

Cancérologie de Montpellier IRCM, Université de Montpellier, ICM, INSERM, 34298

Montpellier, France ${ }^{4}$ BioCampus, RHEM, Université de Montpellier, CNRS, INSERM, 
Montpellier, France ${ }^{5}$ Université Paris Saclay, CEA, INRAE, Département Médicaments et Technologies pour la Santé (DMTS), SPI, 91191 Gif-sur-Yvette, France.

*Correspondence address: Institut de Génétique Humaine, CNRS UMR9002, Université de Montpellier, 141, rue de la Cardonille, 34396 Montpellier Cedex5, France; phone: 33 (4) 3435 9940 


\section{Abstract}

Adenomyosis is characterised by epithelial gland and mesenchymal stroma invasion of the uterine myometrium. Adenomyosis is an oestrogen-dependent gynaecological disease in which a number of factors, such as inflammatory molecules, prostaglandins (PGs), angiogenic factors, cell proliferation and extracellular matrix remodelling proteins also play a role as key disease mediators. In this study, we used mice lacking both L- and $\mathrm{H}$-prostaglandin D synthase (Pgds) genes in which PGD2 is not produced to elucidate PGD2 roles in the uterus. Gene expression studied by realtime PCR and hormone dosages performed by ELISA or liquid chromatography tandem mass spectroscopy (LC-MS/MS) in mouse uterus samples, showed that components of the PGD2 signalling pathway, both PGDS and PGD2-receptors, are expressed in the mouse endometrium throughout the oestrus cycle with some differences among uterine compartments. We showed that PGE2 production and the steroidogenic pathway are dysregulated in the absence of PGD2. Histological analysis of $L / H-P g d s^{-}$uteri, and immunohistochemistry and immunofluorescence analyses of proliferation (Ki67), endothelial cell (CD31), epithelial cell (pan- 
cytokeratin), myofibroblast (a-SMA) and mesenchymal cell (vimentin) markers,

identify that 6-month-old $\mathrm{L} / \mathrm{H}-\mathrm{Pgds} /$ animals developed adenomyotic lesions, and that disease severity increased with age. In conclusion, this study suggests that the PGD2 pathway has major roles in the uterus by protecting the endometrium against adenomyosis development. Additional experiments, using for instance transcriptomic approaches, are necessary to fully determine the molecular mechanisms that lead to adenomyosis in $L / H-P g d s^{-}$mice and to confirm whether this strain is an appropriate model for studying the human disease.

Key words: adenomyosis, endometrium, prostaglandin D2, mouse model, Prostaglandin E2

\section{Introduction}

Adenomyosis is defined as the presence of ectopic endometrial glands and mesenchymal stroma in the uterine myometrium (Benagiano et al., 2014, Bergeron et al., 2006). Conversely, endometriosis is defined as the presence of endometrial tissue (glands and stroma) in organs other than the uterus, such as ovaries, gastrointestinal 
tract and peritoneal cavity. Both diseases are characterised by severe pelvic and abdominal pain (Bozdag, 2015) and contribute to fertility disorders and infertility (Campo et al. , 2012). Adenomyosis/endometriosis affects $10 \%$ of women of reproductive age and is detected in 20 to $50 \%$ of women with infertility (Mahmood and Templeton, 1991, Bozdag, 2015). Adenomyosis pathogenesis is multifactorial and different from that of endometriosis (Guo, 2020). It has been linked to abnormal functions of the endometrial-myometrial interface that comprises the junctional zone (JZ) (Leyendecker et al., 2009, Yen et al., 2017, Tanos et al., 2020). The JZ structure derives embryologically from the paramesonephric ducts, while the remaining myometrium has a mesenchymal origin. Importantly, in the nonpregnant uterus peristalsis originates from the JZ through steroid hormone-dependent stimulations (Lyons et al., 1991). Uterine hyperperistalsis is caused by a physiological stress, such as an increased oestrogen production at the endometrial-JZ and might lead to microtrauma, inflammation and repair (Leyendecker et al., 2009). These tissue injury and repair processes may be responsible for the basal endometrium invagination into the JZ layer and adenomyosis development (Garcia-Solares et al., 2018, Vannuccini et al., 2017). However, adenomyosis pathophysiology is still not fully understood. 
Murine models with genetic modifications enabling the study of adenomyosis have been identified; for example, constitutive activation of $\beta$-catenin (Oh et al., 2013) or FSH receptor haploinsufficiency (Danilovich et al. , 2002) in the uterus, promotes adenomyosis development. Moreover, a heterozygous mutation of the Brca2 gene increases adenomyosis frequency in 6-month-old diethylstilboestrol-treated 129/Sv mice (Bennett et al. , 2000). Furthermore, to identify adenomyosis biomarkers and to develop new targeted and individualised treatments, murine models of adenomyosis have been developed (Bruner-Tran et al., 2018, Greaves and White, 2006,Yen et al., 2017). They include progesterone administration (Ostrander et al. , 1985), anterior pituitary isografting in the uterine lumen leading to overexposure to prolactin (Mori et al. , 1981), short-time exposure to tamoxifen (Green et al. , 2005, Mehasseb et al. , 2009, Parrott et al. , 2001, Shen et al. , 2016), and exposure prenatally or after sexual maturity to the synthetic oestrogen ethynyl oestradiol (Koike et al. , 2013). Exposure to endocrine-disrupting compounds, such as dioxin (Bruner-Tran et al., 2016), diethylstilboestrol (Ostrander et al., 1985) or bisphenolA (Newbold et al., 2007) also has been associated with adenomyosis occurrence in mice (Bruner-Tran et al., 2017). An 
epidemiology study suggested that dioxin exposure might promote adenomyosis development in women (Heilier et al., 2005).

Adenomyosis is an oestrogen-dependent disease, causing chronic inflammation (Kitawaki, 2006), in which a number of factors, such as inflammatory molecules, angiogenic factors, cell proliferation and extracellular matrix remodelling proteins also play a role as key disease mediators (Benagiano et al., 2014). In turn, infiltration of endometrial glands and stroma into the myometrium and hyperestrogenism will activate myometrial peristalsis leading to the activation of the tissue injury and repair mechanism, followed by chronic inflammation (Leyendecker et al., 2009, Guo, 2020). For instance, oestrogen-dependent upregulation of prostaglandin endoperoxide synthase 2 (COX-2) induces excess production of prostaglandin E2 (PGE2) in peritoneal endometriotic lesions (Bulun, 2009, Wu et al., 2007). In turn, PGE2 through its EP2 receptor is a potent inducer of aromatase, specifically in ectopic stromal cells (Bulun, 2009), leading to abnormal oestrogen production. Consequently, the progression and spread of adenomyosis lesions might result from oestrogen-activated epithelial-mesenchymal transition (EMT) through activation of the TGF- $\beta 1$-Smad3 signalling pathway as observed in a mouse model of adenomyosis (Shen et al., 2016) and in human 
adenomyotic tissue samples (Liu et al. , 2016). Prostaglandins are implicated in female reproductive tract physiology, including ovulation, implantation, cervical dilation, menstrual cycle, luteolysis, myometrial contractility, placental vascular tone and parturition (Kennedy et al., 2007, Lim and Dey, 1997, Lim and Dey, 2002). They have been involved in endometrial pathologies such as dysmenorrhoea, endometriosis and uterine adenocarcinoma (Sales and Jabbour, 2003). PGE2 and PGF2 synthases are strongly expressed in human (Catalano et al., 2011), rat (Satoh et al., 2013) and mouse endometrium (Liu et al., 2017). Conversely, prostaglandin D2 (PGD2) synthase expression is lower in human endometrium (Catalano et al., 2011), and PGD2 production is 2-3 times lower than that of PGE2 in rat endometrium (Chaud et al., 1994). In the mouse, the major prostanoid involved in myometrial contraction, is PGD2 (Liu et al., 2017) and has been associated with preterm birth (Kumar et al., 2015). In the porcine uterus, PGD2 antagonises PGE2 and PGF2 $\alpha$ effects and inhibits contraction of the longitudinal muscle layer (Cao et al., 2005). These data suggest that besides PGE2 and PGF2 $\alpha$, PGD2 also has major role(s) in uterine physiology.

PGD2 is produced from the instable precursor PGH2 by two different PGD2 synthases (PGDS) enzymes, Lipocalin and Hematopoietic-type (L-PGDS and $\mathrm{H}$ - 
PGDS) encoded by distinct genes ( $L-$ and $H-P G D S$, official name: PTGDS/Ptgds and HPGDS/Hpgds in the human and mouse genome, respectively but referred to as $L-$ Pgds for Ptgds and H-Pgds for Hpgds, respectively in this manuscript). To elucidate PGD2 roles in the uterus, we analysed the expression of both PGD2 synthases and both PGD2 receptors in the normal mouse uterus and then, characterised the doubleknock-out $\mathrm{L} / \mathrm{H}-\mathrm{Pg} d \mathrm{~s}^{-/}$mouse strain in which PGD2 is not produced due to invalidation of both L-Pgds and H-Pgds genes (Moniot et al., 2014). We found that in L/H-Pgds-1uteri, steroidogenic and prostaglandins pathways were dysregulated, uterine structures (endometrial stroma, JZ and myometrium) were modified, and that $L / H$ -

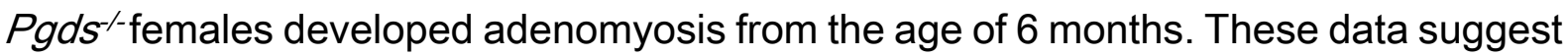
that the PGD2 pathway has major roles in the uterus by protecting the endometrium against adenomyosis development.

\section{Materials and Methods}

\section{$\mathrm{L} / \mathrm{H}-\mathrm{Pgds}^{-}$mouse strain maintenance and tissue collection}


Animal care and handling followed the Réseau des Animaleries de Montpellier (RAM) guidelines and all procedures were approved by the Regional Ethical Committee (agreement number 34366 for B.B.-B.). Double-mutant $\mathrm{L} / \mathrm{H}-\mathrm{Pgds^{-/ }}$ and wild type (WT) $\mathrm{L} / \mathrm{H}-\mathrm{Pgds^{+/ }}$ mice in the $129 / \mathrm{Sv}$ genetic background (Mohri et al., 2006, Trivedi et al., 2006) were housed at the IGH/IGF animal care facility in controlled environmental conditions (light/darkness: $12 \mathrm{~h} / 12 \mathrm{~h}, 23{ }^{\circ} \mathrm{C}$ ). Before sacrifice, the oestrus cycle phase of each female was determined by cytological analysis of a vaginal smear after haematoxylin and eosin (HE) staining (Byers et al., 2012). The proestrus/oestrus stage and metestrus stage were referred as proliferative phase and secretory phase, respectively.

Uteri from 6-, 9- and 12-month-old L/H-Pgds/- and wild type (WT) adult animals (n=16$28, n=10-11$ and $n=5-15$ animals per age and genotype, respectively) were dissected. For each animal, one uterine horn was cut in three pieces that were frozen immediately in dry ice and kept at $-80^{\circ} \mathrm{C}$ until processing (hormone dosages, RT-qPCR, as described below). The second uterine horn was fixed in $4 \mathrm{w} / \mathrm{v} \%$ paraformaldehyde/PBS for paraffin embedding.

\section{Histology, immunofluorescence and immunohistochemistry}

Uterine tissue sections ( $3 \mu \mathrm{m} ; \mathrm{n}=2$ per animal) were cut from paraffin-embedded tissue blocks and were processed for histological analysis after HE staining using standard protocols. The 
presence of histological hallmarks of adenomyosis was investigated under a microscope. Specifically, the severity of the adenomyotic lesions was scored according to the criteria proposed by Bird and colleagues (Bird et al., 1972), as previously described (Shen et al., 2016): Grade 0, normal uterus; Grade 1 (slight adenomyosis), infiltration of endometrial tissue into the surface of the inner myometrium layer; Grade 2 (moderate adenomyosis), invasion of endometrial stroma and glands into the inner myometrium layer; Grade 3 (severe adenomyosis), penetration in the connective tissue between the inner and outer myometrial layers. Uterine adenomyosis frequency in WT and $\mathrm{L} / \mathrm{H}-\mathrm{Pgds}^{-}$animals at each age was quantified as the percentage of animals without adenomyosis (Grade 0 , and with adenomyosis (Grade 1-3) relative to all analysed animals. Collagen deposition was assessed by staining deparaffinised tissue sections with $0.1 \%$ picro-Sirius red solution for $1 \mathrm{~h}$, according to the manufacturer's instructions, followed by rinsing with acidified water and air-drying.

Immunohistochemistry (IHC) was performed using a VENTANA Discovery Ultra automated staining instrument (Ventana Medical Systems, Tuscon, AZ, USA), VENTANA reagents, according to the manufacturer's instructions, and the antibodies listed in Supplementary Table SI. Sections were counterstained with haematoxylin for $4 \mathrm{~min}$ and dehydrated before coverslip addition. Histology and IHC slides were scanned with a 
Nanozoomer Hamamatsu device (Hamamatsu Photonics, Tokyo, Japan) and analysed with the Nanozoomer Digital Pathology (NDPview2) software (Hamamatsu Photonics).

Immunofluorescence (IF) analysis of deparaffinized tissue sections was performed as previously described (Moniot et al., 2009, Rossitto et al., 2019a). Primary and secondary antibodies and their dilutions are listed in Supplementary Table SI. The antibody specificity was confirmed by performing the same IF experiment without primary antibody (not shown). IF images were captured with a Zeiss Axiolmager apotome microscope (Carl Zeiss Microscopy, Jena, Germany) or by scanning slides with a Zeiss AxioScan (Carl Zeiss).

Histology, IHC and IF images were processed with the OMERO software (OMERO. web 5.5.1, University of Dundee and Open Microscopy Environment). Ki67 and CD31 immunostaining of mouse uteri was evaluated using a semi-quantitative scoring system. Five regions of interest (ROIs) in the endometrial stroma, JZ and inner myometrium compartments were randomly selected in three sections of six mouse uteri for each marker. Ki67 and CD31positive cells were segmented using the CellProfiler Software (2.2.0, Broad institute of Harvard, www.cellprofiler.org) (Jones et al., 2008), and the signal intensity was measured. PGDS and CYP19a1 expression levels in mouse uteri $(n=3$ to 5$)$ were quantified with the OMERO software in ROls ( $n=3$ to 4 ) for different uterine compartment. The mean staining 
intensity values from IHC and IF experiments were compared between groups with the Graph Prism8 software (San Diego, CA, USA).

\section{RNA extraction and quantitative realtime RT-PCR}

RNA was extracted from mouse uterine samples $(50-100 \mathrm{mg})$ using Trizol reagent (Thermo Fisher Scientific, Waltham, MA, USA). For each sample ( $n=5$ for each genotype and for each oestrous cycle phase), two independent reverse transcription (RT) (SuperScriptlV; Thermo Fisher Scientific) reactions were done using $800 \mathrm{ng}$ of total RNA, as previously described (Moniot et al., 2009). Real-time PCR runs $(n=3)$ were performed using each RT product on a LightCycler 480 apparatus (Roche Diagnostics) and the primers listed in Supplementary Table SII. 18S was used as a reference gene for PCR data normalization. Data were compared with the GraphPrism 8 software (San Diego, CA, USA).

\section{Progesterone, oestradiol and prostaglandin assays}

Steroids were extracted (twice) from uterine tissue samples (30 to $70 \mathrm{mg}$ ) with diethyl-ether (progesterone or prostaglandins) or methanol (17 $\beta$-oestradiol). After evaporation, extracts were resuspended in EIA buffer (Cayman Chemical, Ann Arbor, MI, USA). Progesterone was quantified in WT and $\mathrm{L} / \mathrm{H}-\mathrm{Pgds} \mathrm{s}^{-}$uteri ( $\mathrm{n}=4$ to 7 for each group) in proliferative and secretory 
phases, by liquid chromatography-tandem mass spectrometry (LC-MS/MS) as described in (Rossitto et al., 2019b). Seventeen $\beta$-oestradiol was quantified in control (WT) (n=6), and $L / H$ Pgds-/ $(\mathrm{n}=6)$ uteri in the proliferative phase using the Oestradiol EIA kit (Cayman Chemical 582251). Prostaglandins (PGD2, PGE2, PGF2 $\alpha, \mathrm{PGI}$ ) in WT and L/H-Pgds-/- uteri ( $\mathrm{n}=4$ to 7 for each group) in proliferative and secretory phases, were quantified using the ProstaglandinD2-MOX, ProstaglandinE2-Express, Prostaglandin F2 $\alpha$ and Prostaglandin I metabolite EIA Kits (Cayman Chemical 512011, 500141, 516011 and 501100, respectively), according to the manufacturer's instructions. Steroid levels were normalised to the uterine sample weight and expressed in $\mathrm{pg} / \mathrm{mg}$ tissue.

\section{Statistical analysis}

Statistical analyses were performed with GraphPrism 8 software (San Diego, CA, USA). For RT-qPCR and for prostaglandin and steroid concentrations, values are the mean \pm SEM of different experiments and of different uterine samples $(n=5)$ for each group. The Student's $t$ test was used to compare WT and $\mathrm{L} / \mathrm{H}-\mathrm{Pg} d \mathrm{~s}^{\star}$ groups in independent experiments, and the one-way analysis of variance (ANOVA) with Tukey post hoc pairwise comparison was used when comparing more than two groups. A P-value $<0.05$ was considered significant $\left({ }^{*} \mathrm{P}<0.05\right.$, $\left.{ }^{* *} \mathrm{P}<0.01,{ }^{* * *} \mathrm{P}<0.005,{ }^{* * * *} \mathrm{P}<0.0001\right)$ 


\section{Results}

\section{Expression of PGD2 synthases in the mouse uterus}

We evaluated L-Pgds and H-Pgds expression by RT-qPCR in 6-month-old WT uteri collected at the proliferative (proestrus/oestrus) and secretory (metestrus) phases. L-Pgds expression was comparable $(P>0.05)$ between phases and was significantly higher $(2.5$-fold $)$ than that of $H$-Pgds in the proliferative phase $(P<0.05)$ but not in the secretory phase (Figure $1 \mathrm{~A})$. Conversely, H-Pgds expression was significantly higher in the secretory (2.8-fold) than proliferative phase $(P<0.005)($ Figure $1 \mathrm{~A})$. Moreover, in mouse uteri, quantification of the IF staining intensity showed that L-PGDS expression in the inner myometrium layer (iml) and JZ was significantly $(P<0.0001$ and $P<0.05$, respectively) higher in the proliferative phase than in the secretory phase. Conversely, L-PGDS expression level in endometrial stroma (ES), and glandular/luminal epithelia (GE/LE) was not significantly different between phases (Figure 1B, C). In the proliferative phase, L-PGDS expression level was significantly higher in the inner iml than in ES $(P<0.01)$ and in LE than in ES $(P<0.05)$. In the secretory phase, the highest LPGDS expression levels were in the LE $(P<0.01$ and $P<0.05$ compared with iml and JZ). $\mathrm{H}$ - 
PGDS protein expression was not oestrus cycle-dependent but in each phase, expression in the LE was significantly higher than in the other compartments $(P<0.0005)$ (Figure 1B, D).

The PGD2 receptors DP1 (Boie et al. , 1995) (Figure 1E) and DP2 ((Hirai et al. , 2001)

(Figure 1F) also were expressed in the different uterine compartments; DP1 expression was similar to H-PGDS expression, and DP2 strongly overlapped with L-PGDS expression. These results show that both PGDS and PGD2-receptors are expressed in the mouse uterus throughout the oestrus cycle with some differences among uterine compartments.

\section{Lack of PGD2 modifies prostaglandin production in $\mathrm{L} / \mathrm{H}-\mathrm{Pgds^{- }}$ uteri}

RT-qPCR quantification showed that uterine expression of the genes encoding the PGI2 (Pgis)

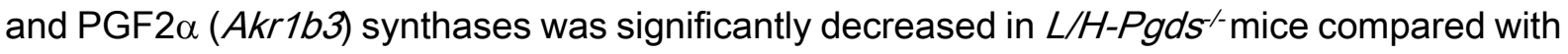
WT samples in the proliferative phase $(P<0.01$ and $P<0.05$, respectively), but not in the secretory phase (Figure 2A and B). Expression of PGE2 synthases (Pges-1, Pges-2 and cPges) was not significantly different between WT and $\mathrm{L} / \mathrm{H}-\mathrm{Pgds}^{-/}$uteri. Conversely, Cox-1 and Cox-2 levels were respectively higher and lower in the proliferative phase, and vice versa in the secretory phase in $\mathrm{L} / \mathrm{H}$-Pgds/-uteri compared with control uteri (Figure $2 \mathrm{~A}$ and $\mathrm{B}$ ). The level of 15-Pgdh (encoding 15-hydroxyprostaglandin dehydrogenase, the major enzyme for

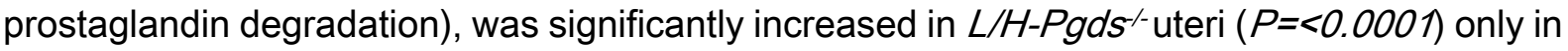


the secretory phase. IF staining indicated that PGES-1 expression level was increased in ES cells and in the hyperplasic LE of $\mathrm{L} / \mathrm{H}-\mathrm{Pgds}^{-/}$uteri compared with control (Supplementary Figure S1A). Moreover, COX-1 and COX-2 levels were significantly increased in $\mathrm{L} / \mathrm{H}-\mathrm{Pgds^{-/ }}$ ES (cytoplasmic localization) $(P<0.0001$ and $P<0.01$, respectively), whereas in LE they did not differ between genotypes (Supplementary Figure S1B-C, Figure 2C).

Consequently, we observed a significant increase of PGE2 level in $\mathrm{L} / \mathrm{H}-\mathrm{Pgds} \mathrm{s}^{-\mathrm{u}}$ uteri in the secretory phase $(P<0.05)$ but not in the proliferative phase uteri $(P>0.05)$ (Figure 2D). Conversely, PGF2 $\alpha$ secretion was not significantly different in WT and $L / H-P g d s^{-}$at both phases, although PGF2 $\alpha$ level tended to decrease in $\mathrm{L} / \mathrm{H}-\mathrm{Pgds^{- }}$ proliferative uteri $(P>0.05)$ (Figure 2E), in agreement with the decreased mRNA expression of its synthase (Akr1b3) (Figure 2A). Also, PGI2 secretion was not modified by $\mathrm{L} / \mathrm{H}-\mathrm{Pg} d s$ invalidation (Figure $2 \mathrm{~F}$ ). Indeed, the level of PGD2 production was significantly lower in $\mathrm{L} / \mathrm{H}-\mathrm{Pg} d \mathrm{~s}^{-}$uteri compared with controls $(P<0.005)$ (Figure 2G).

These results suggested that in $\mathrm{L} / \mathrm{H}-\mathrm{Pgds}^{-/}$mice, the absence of PGD2 production leads to deregulation of PGE2, and to a lesser extent of PGF2 $\alpha$ production.

\section{Impaired steroidogenesis in $\mathrm{L} / \mathrm{H}-\mathrm{Pg} g \mathrm{~s}^{-/}$uteri}

As COX-2-induced PGE2 production is oestrogen-dependent (Wu et al., 2007) and in uterine 
tissue with endometriosis, $17 \beta$-oestradiol (E2) production depends on the local steroid metabolism (Huhtinen et al. , 2012a), we compared the expression of genes implicated in steroidogenesis in WT and $\mathrm{L} / \mathrm{H}-P g d s^{-}$mouse uteri. During the proliferative phase, the genes encoding steroidogenic acute regulatory $(S t A R)(P=0.0001)$, progesterone receptor $(P r)$ $(P<0.05)$ and oestrogen receptors $(E r \alpha$ and $\operatorname{Er} \beta)(P<0.005$ and $P<0.01)$ were significantly upregulated in $\mathrm{L} / \mathrm{H}-\mathrm{Pg} d \mathrm{~s}^{/ /}$uteri compared with controls. Conversely, mRNA expression of the genes encoding cholesterol side-chain cleavage (ScC), P450 aromatase (Cyp19a1) and vascular endothelial growth factor ( Vegf) was comparable between genotypes (Figure 3A).

Steroid quantification showed that uterine E2 concentration was not different between genotypes ( $P>0.05)$, although it was slightly higher in $\mathrm{L} / \mathrm{H}-P g d s^{-}$uteri (Figure 3B). Conversely, progesterone level was significantly decreased in $\mathrm{L} / \mathrm{H}-\mathrm{Pgds}^{-/}$uteri, but only in the proliferative phase ( $P<0.05$ compared with WT) (Figure 3C). However, IF analysis showed a significant upregulation of the P450 aromatase CYP19a1 (the enzyme catalysing E2 production) in LE $(P<0.05)$ and ES cells $(P<0.01)$ in $L / H-P g d s^{--}$uteri in the proliferative phase (Figure 3D and E). The oestrogen receptor ESR1 (ER $\alpha)$ was strongly expressed in the nucleus of endometrial cells (stroma and epithelia) of WT uteri (Supplementary Figure S1D), whereas in L/H-Pgds-1samples, it was mostly localised in the cytoplasm of stromal cells and in the nucleus of epithelial cells (Supplementary Figure S1D). The ESR2 receptor (ER $\beta$ ) was localised in the 
nucleus in proliferative $L / H-P g d s^{-/}$uteri, but was mainly in the cytoplasm of the different cell types in WT uteri (Supplementary Figure S1E).

Oestrogen availability is regulated by the balance between production and metabolism.

Besides CYP19a1 that catalyses E2 synthesis, several 17 $\beta$-hydroxysteroid dehydrogenases (HSD17Bs) contribute to E2 synthesis or metabolism, thus modifying the level of locally available E2 (Delvoux et al. , 2009). We found that $H s d 17 b 7$ was significantly upregulated $(P<0.01)$ whereas $H s d 17 b 2$ was significantly downregulated $(P<0.0001)$ in $L / H-P g d s^{-1-}$ compared with WT uteri (Figure 3F). As HSD17B7 catalyses estrone reduction to E2, and HSD17B2 is involved in E2 inactivation via estrone oxidation, this change may lead to increased E2 level in L/H-Pgds/- uteri. The expression of other Hsd17bs (Hsd17b1, 12, 4 and 10) was not modified in $\mathrm{L} / \mathrm{H}-\mathrm{Pg} d \mathrm{~s}^{-/}$uteri (Figure 3F). Altogether, these results show that in $\mathrm{L} / \mathrm{H}$ Pgds/ uteri, lack of PGD2 profoundly modifies the steroidogenic pathway.

\section{Lack of prostaglandin D2 signalling in $\mathrm{L} / \mathrm{H}-\mathrm{Pgds}^{-}$uteri promotes}

\section{adenomyosis development}

Comparison of WT and $\mathrm{L} / \mathrm{H}-\mathrm{Pg} d \mathrm{~s}^{-/}$females at 6 months of age did not highlight any significant difference in body weight, gross genital tract morphology and fertility. However, histological analysis of 6-month-old WT $(n=16)$ and $L / H-P g d s^{-\sim}(n=28)$ uteri after HE staining (Figure 4A and 
B), showed the presence of focal adenomyosis with endometrium invaginated in the myometrium, in 35\% ( $\mathrm{n}=9$ from 28 ) of $\mathrm{L} / \mathrm{H}$-Pgds ${ }^{-/}$samples (Figure $4 \mathrm{~B}$ and $\mathrm{C}$ ). In these $\mathrm{L} / \mathrm{H}$ Pgds ${ }^{-}$uteri, adenomyosis severity ranged from slight (Grade 1; $\mathrm{n}=6,21.5 \%$ of 28) (Figure 4B1B1'), moderate (Grade 2; n=2, 7.2\%) (Figure 4B2-B2') to severe (Grade 3; $n=1,4 \%$ ) (Figure 4B3-B3') (Figure 4C). In $\mathrm{L} / \mathrm{H}-\mathrm{Pg} d \mathrm{~s}^{+/+}$WT uteri, the endometrium and myometrium layers were well-demarcated (Figure 4A), and adenomyosis lesions were present only in $18.7 \%(n=3$ of 16$)$ of samples (vs 35\% in $\mathrm{L} / \mathrm{H}-\mathrm{Pgds^{ \prime }}$ uteri) (Figure 4C). As the $129 / \mathrm{Sv}$ mouse strain used in this study spontaneously develops adenomyosis at low frequency in adult life (Guttner, 1980), our results show that lack of PGD2 signalling increases its rate in this genetic background.

Adenomyosis frequency strongly increased with age to reach $55 \%$ in 9 -month-old $(n=$ 6/11) (Figure 4C) and 80\% in 12-month-old $(\mathrm{n}=12 / 15) \mathrm{L} / \mathrm{H}-\mathrm{Pgds}^{-/}$animals, while it remained constant $(20 \%)$ in 9-month-old $(n=2 / 10)$ (Figure 4C) and 12-month-old $(n=1 / 5)$ WT mice (Figure 4C and 4D). Disease severity also increased with age. Indeed, 33\% ( $n=5 / 15)$ of 12-month-old L/H-Pgds/- animals presented moderate (Grade 2) (Figure 4E1-E1') and severe (Grade 3) (Figure 4E2-E2') adenomyotic lesions compared with 11\% $(\mathrm{n}=3 / 9)$ of 6-month-old L/H-Pgds ${ }^{-}$ animals (Figure 4C).

We then confirmed the presence of epithelial cells in adenomyotic lesions in 6-monthold $\mathrm{L} / \mathrm{H}-\mathrm{Pgds^{- }}$ uteri by IHC analysis of cytokeratin expression (an epithelial marker) using a pan- 
cytokeratin antibody (Figure 5A). We observed pan-cytokeratin-positive glandular epithelial cells in the iml in $\mathrm{L} / \mathrm{H}-\mathrm{Pgds} \mathrm{s}^{--}$uteri (Figure 5A2) and in focal adenomyotic lesions (Figure 5A3, Adm). $\mathrm{IHC}$ with an antibody against the myofibroblast and smooth muscle marker alpha-Smooth Muscle Actin ( $\alpha-S M A)$ showed strong $\alpha-S M A$ signal in the outer (oml) and inner (iml) myometrium layers in both WT and $\mathrm{L} / \mathrm{H}-\mathrm{Pgds^{- }}$ uteri, as expected (Figure 5B1, 5B2), but also in the endometrial stroma (ES) in $\mathrm{L} / \mathrm{H}-\mathrm{Pg} d \mathrm{~s}^{-/}$uteri (Figure 5B2). Adenomyotic lesions containing pan-cytokeratin-positive glands, were surrounded by cells that strongly expressed $\alpha-S M A$ (Figure 5B3, Adm). Finally, staining with picro-sirius red indicated that in WT uteri, collagen fibres were mainly localised in the myometrium and JZ (Figure 5C1). Conversely, in L/H-Pgds/uteri, picro-sirius red staining became generalised to the ES (Figure $5 \mathrm{C} 2$ ), particularly in areas surrounding adenomyotic lesions (Figure $5 \mathrm{C} 3, \mathrm{Adm}$ ). These results suggest that a fibroblast-tomyofibroblast transdifferentiation (FMT) may occur in the ES of $\mathrm{L} / \mathrm{H}-\mathrm{Pg} d \mathrm{~s}-\mathrm{/}$ - uteri.

We then investigated cell proliferation by IHC with an anti-Ki67 antibody (proliferation marker) (Figure 6A, 6B). The density of Ki67-positive cells was significantly increased in the ES, $\mathrm{JZ}$ and iml of $\mathrm{L} / \mathrm{H}-\mathrm{Pgds}^{-}$uteri compared with WT samples ( $\left.P=<0.0001\right)$ (Figure 6A1-A2, 6B). Expression of CD31 (Figure 6C-6D), a marker of vascular micro-vessels, was significantly increased in the ES, JZ and myometrium of $\mathrm{L} / \mathrm{H}-\mathrm{Pgds}^{-/}$uteri $(P<0.0001)$ (Figure 6C2, 6D). Moreover, in adenomyotic lesions, epithelial and adjacent stromal cells were actively 
proliferating (Figure 6A3, Adm) and were surrounded by a high density of CD31-positive cells (Figure 6C3, Adm), suggesting increased vascularisation in $\mathrm{L} / \mathrm{H}-\mathrm{Pg} d \mathrm{~s}^{-}$uteri. Finally, expression of vimentin, a marker of mesenchymal cells and of EMT was increased in the ES (Figure 6E1) and in adenomyotic lesions (Figure 6E3, Adm), but not in the myometrium of $\mathrm{L} / \mathrm{H}-\mathrm{Pgds}^{-\alpha}$ uteri compared with WT samples.

Altogether, these results indicated that $\mathrm{L} / \mathrm{H}-\mathrm{Pg} d \mathrm{~s}^{\circ}$ uteri display an adenomyosis phenotype characterised by a strong invasion of the inner layer of the myometrium by endometrial and stromal cells.

\section{Discussion}

Adenomyosis is an oestrogen-dependent disease characterised by focal or diffuse presence of endometrial tissue within the uterine myometrium (Bergeron et al., 2006); however, its precise aetiology is unknown. In this study, we found that in $L / H-P g d s^{-1} 129 /$ sv mice, in which both PGD2 synthase genes are invalidated, the frequency of focal adenomyosis lesions at the age of 6 months was significantly higher than in WT animals and that disease severity increased with age. 
Here, we found that both PGDS, which catalyse PGD2 production, are expressed in the cycling mouse uterus, mainly in epithelial and to a lesser extent in stromal cells. H-PGDS protein expression is not dependent on the oestrous phase whereas H-Pgds mRNA is upregulated in the secretory phase, suggesting a post-transcriptional regulation of $\mathrm{H}$-Pgds transcripts. Indeed, H-PGDS has been detected in the female reproductive tract (Urade and Eguchi, 2002, Helliwell et al., 2004). L-PGDS is also strongly expressed in myometrium at the proliferative phase and it is globally 2-fold more expressed at the proliferative than secretory phase. This is in agreement with expression data on human (Catalano et al., 2011, Phillips et al., 2011) and rat uterine samples. Conversely, L-Pgds is expressed in the endometrium at all oestrous phases (Kengni et al., 2007). PGD2 has been involved in different processes of female reproduction (Rossitto et al., 2015, Saito et al., 2002), and produced by the uterus, plays central roles in pregnancy maintenance (Helliwell et al., 2004) and in labour initiation and progression both in humans (Shiki et al., 2004) and in rats (Kengni et al., 2007). PGD2 has been implicated in COX-1-mediated labour initiation and parturition, since it induces prepartum myometrial contraction in vitro through the PGF2 $\alpha$ receptor (FP) (Liu et al., 2017) and in vivo in rat endometrium (Hu et al., 2018). In the non-pregnant uterus, normal peristalsis depends on the responsiveness of prostanoid receptors that are heterogeneously distributed in the longitudinal and circular muscles of the myometrium. The DP1 receptor together with EP2 and 
prostaglandin 12 receptor, is categorised as a relaxant prostanoid receptor, in contrast to the contractile FP, EP1, EP3 receptors (Hu et al., 2018, Cao et al., 2002). The significant expression of both DP receptors in non-pregnant uteri (Catalano et al., 2011, Hu et al., 2018), particularly in the myometrium (Cao et al., 2002, Myatt and Lye, 2004), is in agreement with our data. DP1 and DP2 receptors are expressed in epithelia and DP2 is strongly expressed in the myometrium suggesting additional roles of PGD2 through its own receptors in normal endometrium and myometrium. PGD2 signalling via binding to both DP receptors may interfere with the action of various prostaglandins and of contractile or inhibitory prostanoid receptors, and might play a major role in non-pregnant uterus. The lack of PGD2 in the $\mathrm{L} / \mathrm{H}-\mathrm{Pgds^{- }}$ uteri, particularly in the myometrium, might lead to the dysregulation of the normal myometrium peristalsis, causing microtrauma, an initial hallmark of adenomyosis development.

We found that PGD2 signalling influences the secretion of PGE2 and PGF2 $\alpha$, two prostaglandins that are key factors in the regulation of uterine pathophysiology. PGE2 and PGF2 $\alpha$ have been implicated in endometriosis development, through activation of local oestrogen production (Wu et al., 2007). Furthermore, PGE2 and PGF2 $\alpha$ activate Cox2 expression in a feedback transcriptional loop (Sales et al. , 2008). In the absence of PGD2 production, the decreased secretion of PGF2 $\alpha$ might be in part a response to the decreased Cox2 expression in the proliferative $\mathrm{L} / \mathrm{H}-\mathrm{Pg} d \mathrm{~s}^{-/}$uterus, whereas its up-regulation in the secretory $\mathrm{L} / \mathrm{H}-\mathrm{Pg} d \mathrm{~s}^{-/}$uterus might be 
consecutive to the increased PGE2 secretion. These prostaglandin levels result from the balance between their synthesis and their degradation. All these steps are highly regulated, starting with phospholipase A2 activity that releases arachidonic acid from the cell membrane, and followed by the regulation of COX activities and prostaglandin synthase expression and activities (Seo and Oh, 2017). Their degradation is initiated by their transport via prostaglandin transporter (PGT), and then by 15PGDH, the main prostaglandin catabolizing enzyme that biologically inactivates prostaglandins and related eicosanoids (Tai et al. , 2002). Discrepancies between 15-Pgdh and Cox expression and PGE2/PGF2 $\alpha$ secretion might be due to the prostaglandin synthesis compensation that depends on the availability of the PG precursor PGH2 (Korbecki et al. , 2014). They might also reflect their variation in the different uterine compartments in which differences would not be visible by analyses (RT-qPCR) performed on whole uteri.

In the absence of PGD2, the proliferative activity of stromal, JZ and myometrial cells was increased, highlighting an anti-proliferative action of PGD2. On the other hand, PGE2 induces, through its receptors EP2 and EP4, proliferation of human endometrial epithelial cells (Jabbour and Boddy, 2003), endometriotic cells (Makabe et al., 2020) and in the rat uteri (Kengni et al., 2007, Kothapalli et al., 2003). This is a new example of antagonism between prostaglandins, as previously reported for blood pressure, sleep, labour and inflammatory responses (Helliwell et al., 2004). This antagonism between PGD2 and PGE2 might represent a key feature in the appearance of adenomyosis lesions in $\mathrm{L} / \mathrm{H}-\mathrm{Pgds^{- }}$ uteri. 
In endometriosis, a positive feedback cycle between oestrogen production and inflammation is observed via overexpression of steroidogenic genes such as StAR and Cyp19a1, overexpression of COX2 and PGES1, and local secretion of PGE2 and oestradiol (Huhtinen et al., 2012b, Korbecki et al., 2014, Ricciotti and FitzGerald, 2011). PGE2 production in the endometrial stroma enhances transcription of steroidogenic genes necessary for oestrogen synthesis via cAMP-PKA mediated-EP2 receptor signalling (Attar and Bulun, 2006, Attar et al. , 2009). The increased PGE2 production in $\mathrm{L} / \mathrm{H}-\mathrm{Pgds^{- }}$ uteri might be linked to the up-regulation of StAR that encodes the rate-limiting factor in steroid biosynthesis; however, Scc and Cyp19a1 transcriptional levels were not changed. CYP19a1 upregulation in L/H-Pgds / uteri, without any transcriptional modification of the gene expression via PGE2 (Attar et al., 2009), suggests that PGD2 might be involved in CYP19a1 post-transcriptional/translational regulation or in the regulation of its stability (Ghosh et al., 2019, Molehin et al., 2018). Together with CYP19a1 upregulation, the modified expression of HSD17B2 and HSD17B7, two E2 metabolic enzymes, suggests that the local oestrogen metabolism is modified in the absence of PGD2, as reported in human endometriosis (Attar et al., 2009, Delvoux et al., 2009, Huhtinen et al., 2012b) and adenomyosis (Kitawaki, 2006, Maia et al., 2006, Takahashi et al., 1989). Furthermore, in $\mathrm{L} / \mathrm{H}-\mathrm{Pgds} \mathrm{s}^{-}$uteri, the increase in Esr1 and Esr2 gene expression followed by the increased nuclear localisation of ESR2 might lead to enhanced estrogenic 
response even in the absence of an E2 increase. The differential subcellular localisation of ESR1 and ESR2 is associated with disturbed endometrium and adenomyosis development (Mehasseb et al. , 2011) and is observed in mouse models of adenomyotic uterus (Parrott et al., 2001, Bruner-Tran et al., 2017). However, although steroidogenesis was enhanced in the absence of PGD2, 17 $\beta$-oestradiol production was not significantly increased in $\mathrm{L} / \mathrm{H}-\mathrm{Pgds} \mathrm{s}^{-/}$ uteri, possibly due to different activities of HSD17B7-mediated E2 synthesis and HSD17B2mediated E2 catabolism (Huhtinen et al., 2012b). Conversely, progesterone level was significantly decreased in $\mathrm{L} / \mathrm{H}-\mathrm{Pg} d \mathrm{~s}^{/}$uteri compared with WT controls. This might be related to the decreased HSD17B2 expression as reported in endometriosis (Dassen et al. , 2007). Additional experiments (i.e. high-throughput transcriptomic analysis, in vitro analysis) are needed to evaluate the direct or indirect mechanisms initiated by PGD2 and involved in the post-transcriptional/translational regulation of ESR1-2, COX1, COX2, CYP19a1 (Otto et al., 1993, Wada et al., 2009, Yu and Kim, 2012, Jaen et al., 2018, Molehin et al., 2018, Ghosh et al., 2019), thus affecting their expression, stability and/or their subcellular localisation.

Altogether, our study highlights the role of PGD2 in the mouse uterus pathophysiology, showing that two major pathways (i.e. steroidogenesis and prostaglandins) involved in uterine homeostasis are modified in the absence of PGD2 signalling. In $\mathrm{L} / \mathrm{H}-\mathrm{Pg} d \mathrm{~s}^{-}$uteri, besides the 
alteration of steroidogenesis and its transduction pathways, the modified expression of COX-1, COX-2, PGES-1, CYP19a1, ER $\alpha, E R \beta$ in stromal cells and the upregulation of PGE2 production (Figure 7) lead to increased expression of vimentin, suggesting EMT that might enhance epithelial cells invasiveness (Yen et al., 2017). These features could promote cell proliferation and angiogenesis that in turn, might favour tissue inflammation, injury and hyperperistalsis at the $\mathrm{JZ}$ and myometrium (Figure 7). The increased expression of $\alpha-S M A$ and collagen I in the $\mathrm{L} / \mathrm{H}-\mathrm{Pgds}^{-}$endometrial stroma also suggests myofibroblast differentiation through FMT (Figure 7). These results are also consistent with the presence of $\alpha-S M A$ and collagen I-expressing myofibroblasts and of smooth muscle metaplasia at the endometrium-myometrial JZ leading to adenomyosis development in humans (Ibrahim et al. , 2017), and with adenomyosis and endometrial fibrosis induced by tamoxifen or oestrogen-disruptors in mouse models (Parrott et al., 2001, Green et al., 2005, Mehasseb et al., 2009, Ostrander et al., 1985). In the absence of PGD2, myometrial cells proliferation is increased. Consequently, the altered $\mathrm{L} / \mathrm{H}-\mathrm{Pgds} \mathrm{s}^{-\mathrm{r}}$ myometrium and the disorganised fascicles of smooth muscle, with the lack of a membrane layer between stroma and inner myometrium, might facilitate invasion by the overlying stroma (Naftalin and Jurkovic, 2009, Mehasseb et al. , 2010, Ibrahim et al., 2017). Abnormal myometrium development has been also reported in tamoxifen-induced adenomyosis (BrunerTran et al., 2016). Lack of PGD2 signalling might contribute to the disruption of the inner 
myometrial architecture and function, supporting the hypothesis that adenomyosis is primarily the result of a microtrauma at the junction between endometrium and myometrium (Leyendecker et al., 2009). Secondarily, it predisposes the endometrial stroma and glands to infiltration into the myometrium, two events that occur sequentially in adenomyosis development (Brosens et al. , 1995).

This L/H-Pgds $/$ mouse model allowed showing that lack of PGD2 signalling plays an important role in adenomyosis pathogenesis. Additional experiments, using for instance transcriptomic approaches, are necessary to fully determine the molecular mechanisms that lead to adenomyosis in $\mathrm{L} / \mathrm{H}-\mathrm{Pg} g \mathrm{~s}^{-/}$mice and to confirm whether this strain is an appropriate model for studying adenomyosis. This $L / H-P g d s-/-$ mouse model is one of the first genetic models that can be used to investigate in vivo the molecular and cellular modifications occurring during adenomyosis development and to test adenomyosis treatments. It would be interesting to determine whether a given treatment may revert the observed phenotype. Moreover, as LPGDS is the major PGD2 synthase in the mouse uterus, experiments with single L-or $H$-Pgds mutants are required. 


\section{Acknowledgments}

We thank the technical staff (Morgane Broyon, Aurélie Covinhes, Yoan Buscail, Alicia Seguin and Jean Noël) of the "Réseau d'Histologie Expérimentale de Montpellier" - RHEM facility supported by SIRIC Montpellier Cancer (Grant INCa_Inserm_DGOS_12553), the european regional development foundation and the occitanian region (FEDER-FSE 20142020 Languedoc Roussillon) for processing our animal tissues, histology analysis and expertise. We are grateful to Dr Marie-Pierre Blanchard and Amélie Sarrazin from the IGH Imaging facility (MRI Montpellier) for their help with microscopy analyses. We thank the staff (particularly Quentin Durix, Luc Forichon, Steeve Thirard, Elodie Belan, Karim Mesbah) of the IGH/IGF animal care facility (Réseau des Animaleries de Montpellier, RAM).

\section{Authors' roles}

P. P. designed the study, performed experiments, data analysis and interpretation. S. D. carried out and analysed RT-qPCR, immunofluorescence analysis on mouse uteri, and hormonal dosages. N. P. designed, performed and interpretated histological data and IHC on mouse samples. A. P. designed and interpretated the LC MS/MS experiments. A.-L. N. performed the LC MS/MS experiments. F. B. analysed and interpretated histological data and 
IHC on mouse samples. F. P. interpretated data. B. B.-B. conceived and designed the study, performed data analysis and interpretation. First draft was prepared by B. B.-B. and all authors read the manuscript, revised it and participated in the final version.

\section{Funding}

CNRS and University of Montpellier; National Agency for the Safety of Health Products (ANSM), (Grant 2013-041 to B. B.-B.).

\section{Conflict of Interest}

None of the authors declared a conflict of interest of any kind.

\section{Data Availability Statement}

The data underlying this article are available in the article and in its online supplementary material.The data underlying this article will be shared on reasonable request to the corresponding author. 


\section{References}

535 Attar E, Bulun SE. Aromatase and other steroidogenic genes in endometriosis: translational

536 aspects. Hum Reprod Update 2006;12:49-56.

537 Attar E, Tokunaga H, Imir G, Yilmaz MB, Redwine D, Putman M, Gurates B, Attar R,

538 Yaegashi N, Hales DB et al. Prostaglandin E2 via steroidogenic factor-1 coordinately regulates

539 transcription of steroidogenic genes necessary for estrogen synthesis in endometriosis. $J$ Clin Endocrinol Metab 2009;94:623-631.

541 Benagiano G, Brosens I, Habiba M. Structural and molecular features of the endomyometrium

542 in endometriosis and adenomyosis. Hum Reprod Update 2014;20:386-402.

543 Bennett LM, McAllister KA, Malphurs J, Ward T, Collins NK, Seely JC, Gowen LC, Koller

544 BH, Davis BJ, Wiseman RW. Mice heterozygous for a Brca1 or Brca2 mutation display distinct

545 mammary gland and ovarian phenotypes in response to diethylstilbestrol. Cancer Res

$546 \quad 2000 ; 60: 3461-3469$.

547 Bergeron C, Amant F, Ferenczy A. Pathology and physiopathology of adenomyosis. Best Pract Res Clin Obstet Gynaecol 2006;20:511-521.

549 Bird CC, McElin TW, Manalo-Estrella P. The elusive adenomyosis of the uterus--revisited. Am J Obstet Gynecol 1972;112:583-593.

551 Boie Y, Sawyer N, Slipetz DM, Metters KM, Abramovitz M. Molecular cloning and 552 characterization of the human prostanoid DP receptor. J Biol Chem 1995;270:18910-18916.

553 Bozdag G. Recurrence of endometriosis: risk factors, mechanisms and biomarkers. Womens Health (Lond) 2015;11:693-699.

555 Brosens JJ, de Souza NM, Barker FG. Uterine junctional zone: function and disease. Lancet $556 \quad 1995 ; 346: 558-560$. 
557 Bruner-Tran KL, Duleba AJ, Taylor HS, Osteen KG. Developmental Toxicant Exposure Is 558 Associated with Transgenerational Adenomyosis in a Murine Model. Biol Reprod 2016;95:73. 559 Bruner-Tran KL, Gnecco J, Ding T, Glore DR, Pensabene V, Osteen KG. Exposure to the 560 environmental endocrine disruptor TCDD and human reproductive dysfunction: Translating 561 lessons from murine models. Reprod Toxicol 2017;68:59-71.

562 Bruner-Tran KL, Mokshagundam S, Herington JL, Ding T, Osteen KG. Rodent Models of 563 Experimental Endometriosis: Identifying Mechanisms of Disease and Therapeutic Targets. Curr Womens Health Rev 2018;14:173-188.

565 Bulun SE. Endometriosis. N Engl J Med 2009;360:268-279.

566 Byers SL, Wiles MV, Dunn SL, Taft RA. Mouse estrous cycle identification tool and images. PLoS One 2012;7:e35538.

568 Campo S, Campo V, Benagiano G. Adenomyosis and infertility. Reprod Biomed Online $569 \quad 2012 ; 24: 35-46$.

570 Cao J, Shayibuzhati M, Tajima T, Kitazawa T, Taneike T. In vitro pharmacological 571 characterization of the prostanoid receptor population in the non-pregnant porcine myometrium. Eur J Pharmacol 2002;442:115-123.

573 Cao J, Yosida M, Kitazawa T, Taneike T. Uterine region-dependent differences in 574 responsiveness to prostaglandins in the non-pregnant porcine myometrium. Prostaglandins Other Lipid Mediat 2005;75:105-122.

576 Catalano RD, Wilson MR, Boddy SC, Jabbour HN. Comprehensive expression analysis of 577 prostanoid enzymes and receptors in the human endometrium across the menstrual cycle. $\mathrm{Mol}$ Hum Reprod 2011;17:182-192.

579 Chaud M, Faletti A, Beron de Estrada M, Gimeno AL, Gimeno MA. Synthesis and release of 580 prostaglandins D2 and E2 by rat uterine tissue throughout the sex cycle. Effects of 17-beta581 estradiol and progesterone. Prostaglandins Leukot Essent Fatty Acids 1994;51:47-50. 
Danilovich N, Roy I, Sairam MR. Emergence of uterine pathology during accelerated biological

583

584

585

586

587

588

590

591

592

593

594

595

596

597

598

599

600

601

602

603

604

605 aging in FSH receptor-haploinsufficient mice. Endocrinology 2002;143:3618-3627.

Dassen H, Punyadeera C, Kamps R, Delvoux B, Van Langendonckt A, Donnez J, Husen B, Thole H, Dunselman G, Groothuis P. Estrogen metabolizing enzymes in endometrium and endometriosis. Hum Reprod 2007;22:3148-3158.

Delvoux B, Groothuis P, D'Hooghe T, Kyama C, Dunselman G, Romano A. Increased production of 17 beta-estradiol in endometriosis lesions is the result of impaired metabolism. $J$ Clin Endocrinol Metab 2009;94:876-883.

Garcia-Solares J, Donnez J, Donnez O, Dolmans MM. Pathogenesis of uterine adenomyosis: invagination or metaplasia? Fertil Steril 2018;109:371-379.

Ghosh D, Egbuta C, Kanyo JE, Lam TT. Phosphorylation of human placental aromatase CYP19A1. Biochem J 2019;476:3313-3331.

Greaves P, White IN. Experimental adenomyosis. Best Pract Res Clin Obstet Gynaecol 2006;20:503-510.

Green AR, Styles JA, Parrott EL, Gray D, Edwards RE, Smith AG, Gant TW, Greaves P, AlAzzawi F, White IN. Neonatal tamoxifen treatment of mice leads to adenomyosis but not uterine cancer. Exp Toxicol Pathol 2005;56:255-263.

Guo SW. The Pathogenesis of Adenomyosis vis-a-vis Endometriosis. J Clin Med 2020;9.

Guttner J. Adenomyosis in mice. Z Versuchstierkd 1980;22:249-251.

Heilier JF, Nackers F, Verougstraete V, Tonglet R, Lison D, Donnez J. Increased dioxin-like compounds in the serum of women with peritoneal endometriosis and deep endometriotic (adenomyotic) nodules. Fertil Steril 2005;84:305-312.

Helliwell RJ, Adams LF, Mitchell MD. Prostaglandin synthases: recent developments and a novel hypothesis. Prostaglandins Leukot Essent Fatty Acids 2004;70:101-113. 
Hirai H, Tanaka K, Yoshie O, Ogawa K, Kenmotsu K, Takamori Y, Ichimasa M, Sugamura K,

607 Nakamura M, Takano S et al. Prostaglandin D2 selectively induces chemotaxis in T helper type 6082 cells, eosinophils, and basophils via seven-transmembrane receptor CRTH2. J Exp Med $609 \quad 2001 ; 193: 255-261$.

610 Hu C, Liu B, Li H, Wu X, Guo T, Luo W, Zhou Y. Prostaglandin D2 evokes potent uterine 611 contraction via the F prostanoid receptor in postpartum rats. Eur J Pharmacol 2018;836:11-17.

612 Huhtinen K, Desai R, Stahle M, Salminen A, Handelsman DJ, Perheentupa A, Poutanen M. 613 Endometrial and endometriotic concentrations of estrone and estradiol are determined by local 614 metabolism rather than circulating levels. J Clin Endocrinol Metab 2012a;97:4228-4235.

615 Huhtinen K, Stahle M, Perheentupa A, Poutanen M. Estrogen biosynthesis and signaling in 616 endometriosis. Mol Cell Endocrinol 2012b;358:146-154.

617 Ibrahim MG, Sillem M, Plendl J, Chiantera V, Sehouli J, Mechsner S. Myofibroblasts Are 618 Evidence of Chronic Tissue Microtrauma at the Endometrial-Myometrial Junctional Zone in 619 Uteri With Adenomyosis. Reprod Sci 2017;24:1410-1418.

620 Jabbour HN, Boddy SC. Prostaglandin E2 induces proliferation of glandular epithelial cells of 621 the human endometrium via extracellular regulated kinase 1/2-mediated pathway. J Clin Endocrinol Metab 2003;88:4481-4487. Jaen RI, Prieto P, Casado M, Martin-Sanz P, Bosca L. Post-translational modifications of prostaglandin-endoperoxide synthase 2 in colorectal cancer: An update. World J Gastroenterol 2018;24:5454-5461.

626 Kengni JH, St-Louis I, Parent S, Leblanc V, Shooner C, Asselin E. Regulation of prostaglandin 627 D synthase and prostacyclin synthase in the endometrium of cyclic, pregnant, and 628 pseudopregnant rats and their regulation by sex steroids. J Endocrinol 2007;195:301-311.

629 Kennedy TG, Gillio-Meina C, Phang SH. Prostaglandins and the initiation of blastocyst 630 implantation and decidualization. Reproduction 2007;134:635-643. 
631 Kitawaki J. Adenomyosis: the pathophysiology of an oestrogen-dependent disease. Best Pract Res Clin Obstet Gynaecol 2006;20:493-502.

633 Koike E, Yasuda Y, Shiota M, Shimaoka M, Tsuritani M, Konishi H, Yamasaki H, Okumoto

$634 \mathrm{~K}$, Hoshiai H. Exposure to ethinyl estradiol prenatally and/or after sexual maturity induces 635 endometriotic and precancerous lesions in uteri and ovaries of mice. Congenit Anom (Kyoto) $636 \quad 2013 ; 53: 9-17$.

637 Korbecki J, Baranowska-Bosiacka I, Gutowska I, Chlubek D. Cyclooxygenase pathways. Acta Biochim Pol 2014;61:639-649.

639 Kothapalli D, Stewart SA, Smyth EM, Azonobi I, Pure E, Assoian RK. Prostacylin receptor 640 activation inhibits proliferation of aortic smooth muscle cells by regulating cAMP response 641 element-binding protein- and pocket protein-dependent cyclin a gene expression. Mol Pharmacol 2003;64:249-258.

643 Kumar S, Palaia T, Hall CE, Ragolia L. Role of Lipocalin-type prostaglandin D2 synthase (L644 PGDS) and its metabolite, prostaglandin D2, in preterm birth. Prostaglandins Other Lipid Mediat 2015;118-119:28-33.

646 Leyendecker G, Wildt L, Mall G. The pathophysiology of endometriosis and adenomyosis: 647 tissue injury and repair. Arch Gynecol Obstet 2009;280:529-538.

648 Lim H, Dey SK. Prostaglandin E2 receptor subtype EP2 gene expression in the mouse uterus 649 coincides with differentiation of the luminal epithelium for implantation. Endocrinology $650 \quad 1997 ; \mathbf{1 3 8}: 4599-4606$.

651 Lim H, Dey SK. A novel pathway of prostacyclin signaling-hanging out with nuclear receptors. Endocrinology 2002;143:3207-3210.

653 Liu B, Yang J, Luo W, Zhang Y, Li J, Li H, Chen L, Zhou Y. Prostaglandin D2 is the major 654 cyclooxygenase-1-derived product in prepartum mouse uteri where it mediates an enhanced in 655 vitro myometrial contraction. Eur J Pharmacol 2017;813:140-146. 
656 Liu X, Shen M, Qi Q, Zhang H, Guo SW. Corroborating evidence for platelet-induced 657 epithelial-mesenchymal transition and fibroblast-to-myofibroblast transdifferentiation in the 658 development of adenomyosis. Hum Reprod 2016;31:734-749.

659 Lyons EA, Taylor PJ, Zheng XH, Ballard G, Levi CS, Kredentser JV. Characterization of 660 subendometrial myometrial contractions throughout the menstrual cycle in normal fertile 661 women. Fertil Steril 1991;55:771-774.

662 Mahmood TA, Templeton A. Prevalence and genesis of endometriosis. Hum Reprod $663 \quad 1991 ; 6: 544-549$.

664 Maia H, Jr., Casoy J, Correia T, Freitas L, Pimentel K, Athayde C, Coutinho E. Effect of the 665 menstrual cycle and oral contraceptives on aromatase and cyclooxygenase- 2 expression in 666 adenomyosis. Gynecol Endocrinol 2006;22:547-551.

667 Makabe T, Koga K, Nagabukuro H, Asada M, Satake E, Taguchi A, Takeuchi A, Miyashita M, 668 Harada M, Hirata T et al. Use of selective PGE2 receptor antagonists on human endometriotic 669 stromal cells and peritoneal macrophages. Mol Hum Reprod 2020.

670 Mehasseb MK, Bell SC, Habiba MA. The effects of tamoxifen and estradiol on myometrial 671 differentiation and organization during early uterine development in the CD1 mouse. Reproduction 2009;138:341-350.

673 Mehasseb MK, Bell SC, Pringle JH, Habiba MA. Uterine adenomyosis is associated with 674 ultrastructural features of altered contractility in the inner myometrium. Fertil Steril $675 \quad 2010 ; 93: 2130-2136$.

676 Mehasseb MK, Panchal R, Taylor AH, Brown L, Bell SC, Habiba M. Estrogen and 677 progesterone receptor isoform distribution through the menstrual cycle in uteri with and without 678 adenomyosis. Fertil Steril 2011;95:2228-2235, 2235 e2221. 
$680 \mathrm{~S}$, Kim HS, Urade $\mathrm{Y}$ et al. Lipocalin-type prostaglandin D synthase is up-regulated in 681 oligodendrocytes in lysosomal storage diseases and binds gangliosides. J Neurochem 2006.

682 Molehin D, Castro-Piedras I, Sharma M, Sennoune SR, Arena D, Manna PR, Pruitt K. 683 Aromatase Acetylation Patterns and Altered Activity in Response to Sirtuin Inhibition. Mol Cancer Res 2018;16:1530-1542.

685 Moniot B, Declosmenil F, Barrionuevo F, Scherer G, Aritake K, Malki S, Marzi L, Cohen686 Solal A, Georg I, Klattig J et al. The PGD2 pathway, independently of FGF9, amplifies SOX9 687 activity in Sertoli cells during male sexual differentiation. Development 2009;136:1813-1821. 688 Moniot B, Ujjan S, Champagne J, Hirai H, Aritake K, Nagata K, Dubois E, Nidelet S, 689 Nakamura M, Urade Y et al. Prostaglandin D2 acts through the Dp2 receptor to influence male 690 germ cell differentiation in the foetal mouse testis. Development 2014;141:3561-3571.

691 Mori T, Nagasawa H, Takahashi S. The induction of adenomyosis in mice by intrauterine 692 pituitary isografts. Life Sci 1981;29:1277-1282.

693 Myatt L, Lye SJ. Expression, localization and function of prostaglandin receptors in 694 myometrium. Prostaglandins Leukot Essent Fatty Acids 2004;70:137-148.

695 Naftalin J, Jurkovic D. The endometrial-myometrial junction: a fresh look at a busy crossing. Ultrasound Obstet Gynecol 2009;34:1-11.

697 Newbold RR, Jefferson WN, Padilla-Banks E. Long-term adverse effects of neonatal exposure 698 to bisphenol A on the murine female reproductive tract. Reprod Toxicol 2007;24:253-258.

699 Oh SJ, Shin JH, Kim TH, Lee HS, Yoo JY, Ahn JY, Broaddus RR, Taketo MM, Lydon JP, 700 Leach RE et al. beta-Catenin activation contributes to the pathogenesis of adenomyosis through 701 epithelial-mesenchymal transition. J Pathol 2013;231:210-222. 
Ostrander PL, Mills KT, Bern HA. Long-term responses of the mouse uterus to neonatal diethylstilbestrol treatment and to later sex hormone exposure. J Natl Cancer Inst 1985;74:121135.

Otto JC, DeWitt DL, Smith WL. N-glycosylation of prostaglandin endoperoxide synthases-1 and -2 and their orientations in the endoplasmic reticulum. J Biol Chem 1993;268:18234-18242. Parrott E, Butterworth M, Green A, White IN, Greaves P. Adenomyosis--a result of disordered stromal differentiation. Am J Pathol 2001;159:623-630.

Phillips RJ, Al-Zamil H, Hunt LP, Fortier MA, Lopez Bernal A. Genes for prostaglandin synthesis, transport and inactivation are differentially expressed in human uterine tissues, and the prostaglandin F synthase AKR1B1 is induced in myometrial cells by inflammatory cytokines. Mol Hum Reprod 2011;17:1-13.

Ricciotti E, FitzGerald GA. Prostaglandins and inflammation. Arterioscler Thromb Vasc Biol 2011;31:986-1000.

Rossitto M, Marchive C, Pruvost A, Sellem E, Ghettas A, Badiou S, Sutra T, Poulat F, Philibert P, Boizet-Bonhoure B. Intergenerational effects on mouse sperm quality after in utero exposure to acetaminophen and ibuprofen. FASEB J 2019a;33:339-357.

Rossitto M, Ollivier M, Dejardin S, Pruvost A, Brun C, Marchive C, Nguyen AL, Ghettas A, Keime C, de Massy B et al. In utero exposure to acetaminophen and ibuprofen leads to intergenerational accelerated reproductive aging in female mice. Commun Biol 2019b;2:310.

Rossitto M, Ujjan S, Poulat F, Boizet-Bonhoure B. Multiple roles of the prostaglandin D2 signaling pathway in reproduction. Reproduction 2015;149:R49-58.

Saito S, Tsuda H, Michimata T. Prostaglandin D2 and reproduction. Am J Reprod Immunol 2002;47:295-302. 
Sales KJ, Grant V, Jabbour HN. Prostaglandin E2 and F2alpha activate the FP receptor and up-

726 regulate cyclooxygenase-2 expression via the cyclic AMP response element. Mol Cell Endocrinol 2008;285:51-61.

728 Sales KJ, Jabbour HN. Cyclooxygenase enzymes and prostaglandins in reproductive tract 729 physiology and pathology. Prostaglandins Other Lipid Mediat 2003;71:97-117.

730 Satoh H, Watanabe K, Kawaminami M, Kurusu S. A comprehensive immunohistochemistry of 731 prostaglandins F2alpha and E2 synthetic enzymes in rat ovary and uterus around parturition. Prostaglandins Other Lipid Mediat 2013;106:23-28.

733 Seo MJ, Oh DK. Prostaglandin synthases: Molecular characterization and involvement in 734 prostaglandin biosynthesis. Prog Lipid Res 2017;66:50-68.

735 Shen M, Liu X, Zhang H, Guo SW. Transforming growth factor beta1 signaling coincides with 736 epithelial-mesenchymal transition and fibroblast-to-myofibroblast transdifferentiation in the 737 development of adenomyosis in mice. Hum Reprod 2016;31:355-369.

738 Shiki Y, Shimoya K, Tokugawa Y, Kimura T, Koyama M, Azuma C, Murata Y, Eguchi N, Oda $739 \mathrm{H}$, Urade Y. Changes of lipocalin-type prostaglandin D synthase level during pregnancy. $J$ Obstet Gynaecol Res 2004;30:65-70.

741 Tai HH, Ensor CM, Tong M, Zhou H, Yan F. Prostaglandin catabolizing enzymes. Prostaglandins Other Lipid Mediat 2002;68-69:483-493.

743 Takahashi K, Nagata H, Kitao M. Clinical usefulness of determination of estradiol level in the 744 menstrual blood for patients with endometriosis. Nihon Sanka Fujinka Gakkai zasshi 745 1989;41:1849-1850.

746 Tanos V, Lingwood L, Balami S. Junctional Zone Endometrium Morphological Characteristics 747 and Functionality: Review of the Literature. Gynecol Obstet Invest 2020;85:107-117. 
748 Trivedi SG, Newson J, Rajakariar R, Jacques TS, Hannon R, Kanaoka Y, Eguchi N, Colville-

749 Nash P, Gilroy DW. Essential role for hematopoietic prostaglandin D2 synthase in the control

750 of delayed type hypersensitivity. Proc Natl Acad Sci U S A 2006;103:5179-5184.

751 Urade Y, Eguchi N. Lipocalin-type and hematopoietic prostaglandin D synthases as a novel 752 example of functional convergence. Prostaglandins \& other lipid mediators 2002;68-69:375753382.

754 Vannuccini S, Tosti C, Carmona F, Huang SJ, Chapron C, Guo SW, Petraglia F. Pathogenesis 755 of adenomyosis: an update on molecular mechanisms. Reprod Biomed Online 2017;35:592-601.

756 Wada M, Saunders TL, Morrow J, Milne GL, Walker KP, Dey SK, Brock TG, Opp MR, 757 Aronoff DM, Smith WL. Two pathways for cyclooxygenase-2 protein degradation in vivo. $J$ Biol Chem 2009;284:30742-30753.

759 Wu MH, Shoji Y, Chuang PC, Tsai SJ. Endometriosis: disease pathophysiology and the role of 760 prostaglandins. Expert Rev Mol Med 2007;9:1-20.

761 Yen CF, Huang SJ, Lee CL, Wang HS, Liao SK. Molecular Characteristics of the Endometrium 762 in Uterine Adenomyosis and Its Biochemical Microenvironment. Reprod Sci 2017;24:13467631361.

764 Yu SM, Kim SJ. Protein phosphorylation on tyrosine restores expression and glycosylation of 765 cyclooxygenase-2 by 2-deoxy-D-glucose-caused endoplasmic reticulum stress in rabbit 766 articular chondrocyte. BMB Rep 2012;45:317-322. 


\section{LEGENDS to Figures}

Figure 1 Expression of prostaglandin D2 synthases in wild type mouse uterus. (A) L-Pgds and H-Pgds gene expression were analysed by real time quantitative RT-PCR in mouse uteri collected at proliferative (P) and secretory $(S)$ phases of the oestrous cycle. Results were normalised to $18 S$ mRNA level and were compared with the Student's $t$ test; ${ }^{*} \mathrm{P}<0.05$, ${ }^{* * *} P<0.005$. (B) Quantification of L-PGDS and H-PGDS staining intensity in the inner myometrium layer (iml), junctional zone (JZ), endometrial stroma (ES), glandular epithelium (GE) and luminal epithelium (LE) ( $n=3$ to 4 regions of interest for each compartment) of proliferative and secretory mouse uterus samples. Staining intensities are the mean $+/-$ SEMs for $n=3-5$ uterine samples/phase. $P$-values: ${ }^{*} P<0.05$, ${ }^{* *} P<0.01$, ${ }^{* * *} P<0.005$, ${ }^{* * *} P<0.0001$. (CD) Representative immunofluorescence panels of L-PGDS (C) and H-PGDS (D) expression in proliferative and secretory mouse uterus samples. Uterine tissue sections were incubated with rabbit antibodies against L-PGDS (C) and H-PGDSs (D) (in red), and nuclei were stained with the Hoescht dye (HST, in blue). (E-F) Representative immunofluorescence panels of DP1 (E) and DP2 $(F)$ expression (in red) in proliferative mouse uterus samples. Nuclei were stained with the Hoescht dye (HST, in blue). iml: inner myometrium layer; JZ: junctional zone; ES: endometrial stroma; GE: glandular epithelium and LE: luminal epithelium. Dashed lines 
delineate the $\mathrm{JZ}$ between $\mathrm{ES}$ and $\mathrm{iml}$, and areas in the dashed squares are enlarged on the right panels. Scale bars: $150 \mu \mathrm{m}(\mathrm{C}-\mathrm{F})$.

Figure 2 Prostaglandin pathways are modified in $\mathrm{L} / \mathrm{H}-\mathrm{Pg} d \mathrm{~s}^{-}$-uteri. (A-B) Real-time quantitative RT-PCR analysis of genes encoding factors involved in prostaglandin synthesis in proliferative (A) and secretory (B) wild type (WT, in black) and $\mathrm{L} / \mathrm{H}-\mathrm{Pgds}^{--}$(KO, in grey) uteri. Data were normalised to 18 S expression. (A-B) Relative qPCR expression values are the mean +/- SEMs of 5 samples/genotype. P-values: ${ }^{*} \mathrm{P}<0.05,{ }^{* *} \mathrm{P}<0.01, \quad{ }^{* * *} \mathrm{P}<0.005, \quad{ }^{* * * *} \mathrm{P}<0.0001$. (C) Quantification of COX-1 and COX-2 staining intensity in the endometrial stroma (ES) and luminal epithelium (LE) ( $n=3$ to 4 regions of interest for each compartment) of proliferative WT and $\mathrm{KO}$ uterus samples. Staining intensities are the mean $+/-$ SEMs of $n=3-5$ uterine samples/genotype. P-values: ${ }^{* *} P<0.01,{ }^{* * *} P<0.0001$. (D-G) Dosage by ELISA of PGE2 (D), PGF2 $\alpha(E)$ PGI2 (F) and PGD2 (G) in proliferative and secretory WT and $\mathrm{L} / \mathrm{H}-\mathrm{Pgds}^{\circ-}(\mathrm{KO})$ uteri ( $n=4$ to 7 for prostaglandin dosage). For PGD2 levels, data are represented as the sum of proliferative and secretory values for WT and KO uteri (G). Prostaglandin levels (mean \pm SEMs) were normalised to tissue weight and expressed in $\mathrm{pg} / \mathrm{mg}$ tissue. 
Figure 3 Steroidogenesis is modified in $\mathrm{L} / \mathrm{H}-\mathrm{Pgds}^{-}$uteri. (A) Real time quantitative RT-PCR analysis of steroidogenic gene levels normalised to 185 expression in proliferative wild type (WT, in black) and $\mathrm{L} / \mathrm{H}-\mathrm{Pgds}^{-/}$(KO, in grey) uteri. (B-C) 17ß-oestradiol (E2) (B) was quantified in proliferative control (WT) and $\mathrm{L} / \mathrm{H}-\mathrm{Pgds^{ \circ }}$ uteri ( $\mathrm{n}=6 /$ genotype) by ELISA and progesterone (C) was quantified in proliferative and secretory control (WT) and $L / H-P g d s^{-/}$(KO) uteri (n=4 to $7 /$ genotype) by LC-MS/MS. Steroid levels were normalised to the tissue weight and expressed in $\mathrm{pg} / \mathrm{mg}$ tissue and represent the mean \pm SEMs. (D) Representative immunofluorescence images of CYP19a1 expression localisation in $\mathrm{L} / \mathrm{H}-\mathrm{Pgds^{+/+ }}$ and $\mathrm{L} / \mathrm{H}-\mathrm{Pgds}$ - uteri in the proliferative phase of the oestrous cycle. Areas in the dashed white squares are enlarged in the lower panels. ES: endometrial stroma; GE: glandular epithelium and LE: luminal epithelium. Scale bar= $150 \mu \mathrm{m}$. (E) Quantification of CYP19a1 staining intensity in the endometrial stroma (ES), and luminal epithelium (LE) ( $n=3$ to 4 ROls for each compartment) of proliferative WT and KO uterus samples. Staining intensities are the mean $+/-$ SEMs of $n=3$ 5 uterine samples/genotype. P-values: ${ }^{*} P<0.05,{ }^{* *} P<0.01$. (F) Real time quantitative RT-PCR analysis of $H s d 17 B$ gene levels normalised to $18 S$ expression in proliferative wild type (WT, in black) and $\mathrm{L} / \mathrm{H}-\mathrm{Pgds}^{-/}(\mathrm{KO}$, in grey) uteri. (A, F) Relative qPCR expression values are the mean +/- SEMs of 5 samples/genotype. P-values: ${ }^{*} P<0.05, \quad{ }^{* *} P<0.01, \quad{ }^{* * *} P<0.005$, ${ }^{* * * *} \mathrm{P}<0.0001$ 
Figure 4 In L/H-Pgds/-females, lack of PGD2 promotes adenomyosis. (A-B) Representative images of uterus samples from 6-month-old wild type $\mathrm{L} / \mathrm{H}-\mathrm{Pgds} \mathrm{s}^{++}(\mathrm{A})$ and mutant $\mathrm{L} / \mathrm{H}-\mathrm{Pg} d \mathrm{~s}^{--}$ (B) females after haematoxylin-eosin staining. The area within the dashed purple squares in the upper panels (A1, B1-B3) is enlarged in the lower panels (A1', B1'-B3') to visualise the endometrium/myometrium junction ( $\mathrm{JZ}$, dashed black line) and to highlight adenomyotic lesions (black arrows) in $\mathrm{L} / \mathrm{H}-\mathrm{Pgds}^{/-}$uteri (B); Representative lesions are shown, Grade 1 (slight adenomyosis) (B1-B1'); Grade2 (moderate adenomyosis) (B2-B2') and Grade 3 (severe adenomyosis) (B3-B3'). (C) Histogram showing adenomyosis frequency in $\mathrm{L} / \mathrm{H}_{-} \mathrm{Pgds}^{+/+}$(WT) and $\mathrm{L} / \mathrm{H}-\mathrm{Pgds}^{\circ}$ (KO) females at the indicated ages (m: months). Adenomyosis frequency was expressed as the percentage of animals without adenomyosis (Grade 0), Grade 1, Grade 2 and Grade 3 lesions relative to all analysed mice. (D-E) Representative images of uterus samples from 12-month-old $\mathrm{L} / \mathrm{H}-\mathrm{Pgds}^{+/+}(\mathrm{D})$ and $\mathrm{L} / \mathrm{H}-\mathrm{Pgds}^{-/}(\mathrm{E})$ females after haematoxylineosin staining. The dashed black line delineates the $\mathrm{JZ}$ at the endometrium/myometrium junction (D) and the area within dashed purple squares (D1, E1-E2) is enlarged in the lower panels (D1', E1'-E2') to show adenomyotic lesions (black arrows). (A-B, D-E) oml: outer myometrium layer; iml: inner myometrium layer; JZ: junctional zone; ES: endometrial stroma; 
GE: glandular epithelium and LE: luminal epithelium. Scale bars: $300 \mu \mathrm{m}$ (A-B 1-3, D-E 1-2) and $150 \mu \mathrm{m}(\mathrm{A} 1$ ', B1'-B3', D1', E1'-E2').

Figure 5 Characterisation of the $\mathrm{L} / \mathrm{H}-\mathrm{Pgds^{- }}$ uterus phenotype. (A-B) Representative immunohistochemistry images of pan-cytokeratin (A) and $\alpha-S m a(B)$ expression in serial sections in the uterus of 6-month-old $\mathrm{L} / \mathrm{H}-\mathrm{Pgds}^{+/+}$and $\mathrm{L} / \mathrm{H}-\mathrm{Pgds} \mathrm{s}^{-/}$females at the proliferative stage of the oestrous cycle and in an adenomyotic uterus (L/H-Pgds-/- Adm); (C) Representative images of picro-sirius red staining highlighting collagen fibres in uteri from $L / H$ $P_{g d s^{+/+}}$and $\mathrm{L} / \mathrm{H}-P g d s^{/-}$females and in an adenomyotic uterus ( $\left.\mathrm{L} / \mathrm{H}-\mathrm{Pg} \mathrm{d}^{\mathrm{s}^{-/}} \mathrm{Adm}\right)$ at the proliferative stage of the oestrous cycle. Black arrows $(A-C)$ indicate adenomyotic lesions in L/H-Pgds/- uteri. (A-C) Oml: outer myometrium layer; iml: inner myometrium layer; JZ: junctional zone; ES: endometrial stroma; GE: glandular epithelium; LE: luminal epithelium. Scale bars: $300 \mu \mathrm{m}(\mathrm{A}-\mathrm{C})$.

Figure 6 Adenomyosis biomarker identification in $\mathrm{L} / \mathrm{H}-\mathrm{Pg} d \mathrm{~s}^{-}$uteri. Representative immunostaining images of Ki67 (A) and CD31 (C) expression in 6-month-old $\mathrm{L} / \mathrm{H}-\mathrm{Pgds} \mathrm{s}^{+/+}$and $\mathrm{L} / \mathrm{H}-\mathrm{Pgds}^{\sim}$ uteri, and in adenomyotic lesions $\left(\mathrm{L} / \mathrm{H}-\mathrm{Pgds}^{-/} \mathrm{Adm}\right)$. Dashed black lines delineate the junctional zone (JZ) between endometrial stroma and myometrium. Black arrows highlight 
proliferating cells $(\mathrm{A})$ and blood micro-vessels $(\mathrm{B})$; black arrowheads identify adenomyotic lesions. Scale bar= $150 \mu \mathrm{m}$. (B, D) Quantification of Ki67 (B) and CD31 (D) staining density in the endometrial stroma (ES)-junctional zone (JZ) and inner myometrium (iml) of L/H-Pgds ${ }^{+/+}$ (WT) and L/H-Pgds/ (KO) uteri. Data are shown as the mean +/- SEMs ( $\mathrm{n}=3$ to 6 ROIs overlapping the ES-JZ-iml zones) of WT and KO uteri ( $n=5 /$ genotype). P-values: ${ }^{* * * *} \mathrm{P}<0.0001$. (E) Representative immunofluorescence images of vimentin expression (in red) in 6-month-old $\mathrm{L} / \mathrm{H}-\mathrm{Pgds}^{+/+}$and $\mathrm{L} / \mathrm{H}-\mathrm{Pgds}^{-/}$uteri, and adenomyotic lesions ( $\left.\mathrm{L} / \mathrm{H}-\mathrm{Pgds^{-/ }} \mathrm{Adm}\right)$; nuclei were stained with Hoescht (HST, in blue). Dashed white lines delineate the endometrial stroma/myometrium junction. White arrow identifies an adenomyotic lesion. Oml: outer myometrium layer; iml: inner myometrium layer; ES: endometrial stroma; GE: glandular epithelium and LE: luminal epithelium. Scale bars: $300 \mu \mathrm{m}(\mathrm{A}-\mathrm{C})$.

Figure 7 Model of adenomyotic lesion formation in the absence of PGD2 signalling. In the nonpregnant uterus, PGDS synthases produce PGD2, in the endometrial stroma, junctional zone and myometrium. In $\mathrm{L} / \mathrm{H}-\mathrm{Pg} d \mathrm{~s}^{-}$uteri, in the absence of PGD2 signalling, PGE2 secretion is increased and COX-2 protein expression is up-regulated. Similarly, the StAR gene, which encodes the rate-limiting factor in steroid biosynthesis, is up-regulated. Moreover, the expression of $17 H s d b s$ genes, which encode E2 metabolic enzymes is modified, the protein 
level of CYP19a1 is increased and the subcellular localisation of ER $\alpha, E R \beta$ are modified, in the endometrial stroma. These modified prostaglandin pathways and steroidogenesis lead to the induction of endometrial and myometrial cell proliferation, angiogenesis, and overexpression of vimentin and $\alpha-S M A$ and collagen deposition in the endometrial stroma, inducing epithelial-mesenchymal transition (EMT) and fibroblast-mesenchymal transition (FMT) in the endometrial stroma and endometrial-myometrium junctional zone. These features, induced directly or indirectly by the lack of PGD2, may contribute to inflammatory stimulation, uterine hyperperistalsis and injury, thus increasing the susceptibility to endometrial gland invagination and adenomyosis formation in the myometrium of $\mathrm{L} / \mathrm{H}-\mathrm{Pgds} \mathrm{s}^{-\mathrm{u}}$ uteri.

Supplementary Figure S1 Representative immunofluorescence images of PGES-1 (A, in red), COX-1 (B, in green), COX-2 (C, in red), ER $\alpha(D$, in green) and $E R \beta(E$, in green) localisation in $\mathrm{L} / \mathrm{H}-\mathrm{Pgds} \mathrm{s}^{+/+}$and $\mathrm{L} / \mathrm{H}-\mathrm{Pg} d \mathrm{~s}^{-/}$uteri at the proliferative stage of the oestrous cycle. Nuclei were stained with Hoescht (HST, in blue). iml: inner myometrium layer; JZ: junctional zone; ES: endometrial stroma; GE: glandular epithelium and LE: luminal epithelium. Scale bar= $100 \mu \mathrm{m}$. 


\section{6}

897

898 
B

A
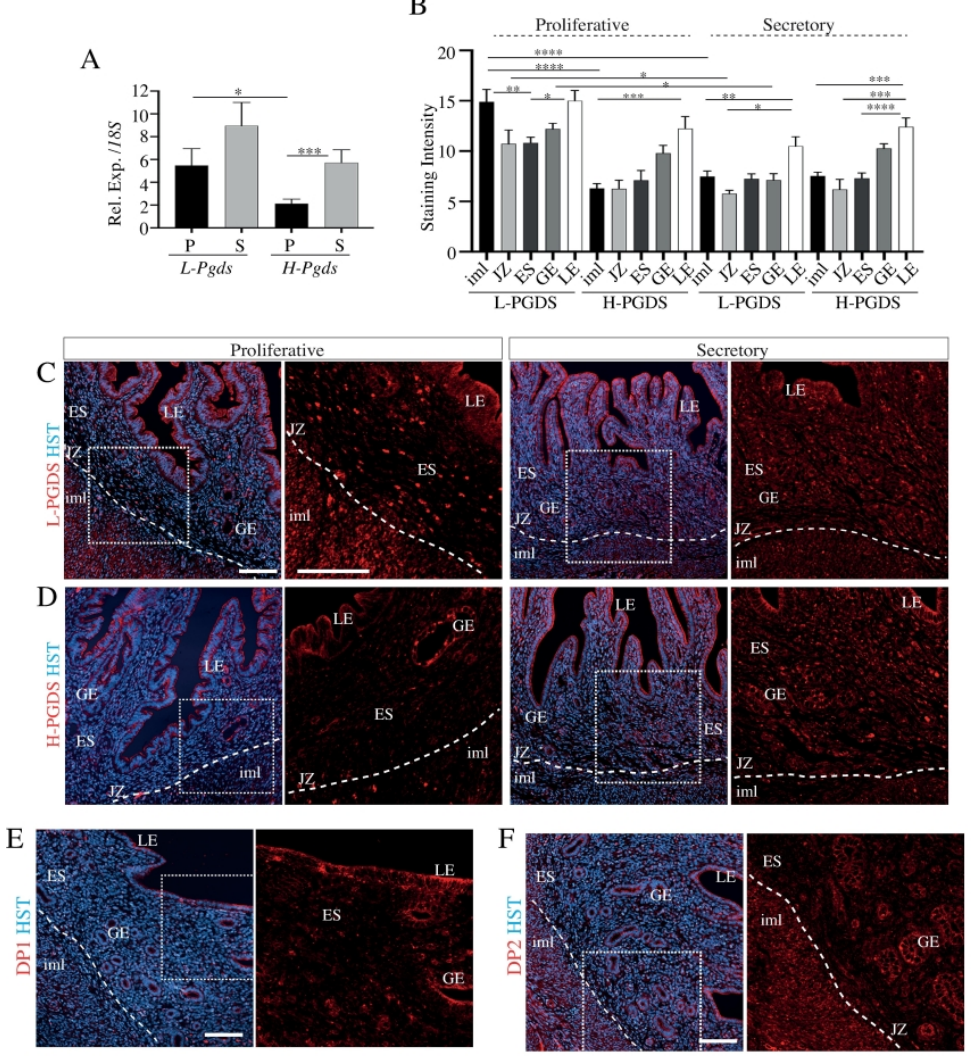

Figure 1

Figure 1 Expression of prostaglandin D2 synthases in wild type mouse uterus. (A) L-Pgds and H-Pgds gene expression were analysed by real time quantitative RT-PCR in mouse uteri collected at proliferative $(P)$ and secretory $(S)$ phases of the oestrous cycle. Results were normalised to $18 \mathrm{~S}$ mRNA level and were compared with the Student's t test; *P<0.05, ***P<0.005. (B) Quantification of L-PGDS and H-PGDS staining intensity in the inner myometrium layer (iml), junctional zone (JZ), endometrial stroma (ES), glandular epithelium

(GE) and luminal epithelium (LE) ( $n=3$ to 4 ROIs for each compartment) of proliferative and secretory mouse uterus samples. Staining intensities are the mean $+/-$ SEMs for $n=3-5$ uterine samples/phase. Pvalues: $* \mathrm{P}<0.05, * * \mathrm{P}<0.01, * * * \mathrm{P}<0.005, * * * * \mathrm{P}<0.0001$. (C-D) Representative immunofluorescence panels

of L-PGDS (C) and H-PGDS (D) expression in proliferative and secretory mouse uterus samples. Uterine tissue sections were incubated with rabbit antibodies against L-PGDS (C) and H-PGDSs (D) (in red), and nuclei were stained with the Hoescht dye (HST, in blue). (E-F) Representative immunofluorescence panels of DP1 (E) and DP2 (F) expression (in red) in proliferative mouse uterus samples. Nuclei were stained with the Hoescht dye (HST, in blue). iml: inner myometrium layer; JZ: junctional zone; ES: endometrial stroma; GE: glandular epithelium and LE: luminal epithelium. Dashed lines delineate the JZ between ES and iml, and 
areas in the dashed squares are enlarged on the right panels. Scale bars: $150 \square \mathrm{m}$ (C-F). $252 \times 304 \mathrm{~mm}(600 \times 600 \mathrm{DPI})$ 


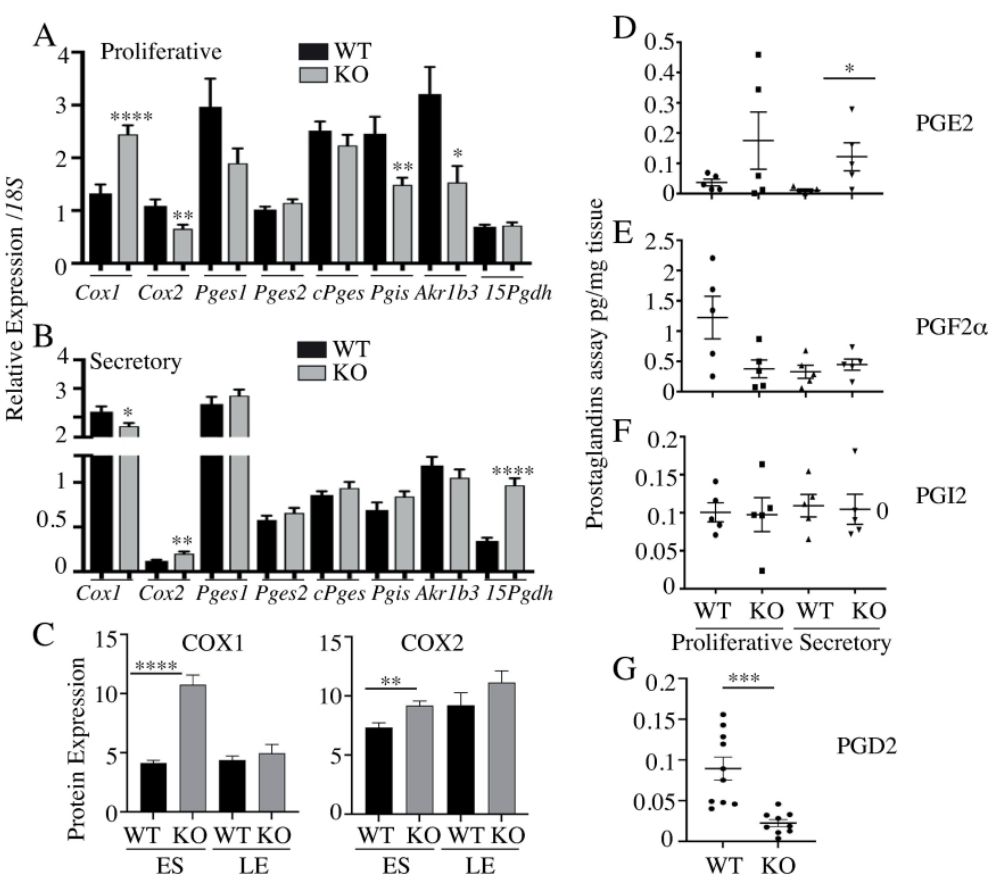

Figure 2

Figure 2 Prostaglandin pathways are modified in L/H-Pgds-/- uteri. (A-B) Real-time quantitative RT-PCR analysis of genes encoding factors involved in prostaglandin synthesis in proliferative $(A)$ and secretory (B) wild type (WT, in black) and L/H-Pgds-/- (KO, in grey) uteri. Data were normalised to $18 \mathrm{~S}$ expression. (A-B)

Relative qPCR expression values are the mean +/- SEMs of 5 samples/genotype. P-values: $* P<0.05$, $* * \mathrm{P}<0.01, * * * \mathrm{P}<0.005, * * * * \mathrm{P}<0.0001$. (C) Quantification of COX-1 and COX-2 staining intensity in the endometrial stroma (ES) and luminal epithelium (LE) ( $n=3$ to 4 ROIs for each compartment) of proliferative WT and KO uterus samples. Staining intensities are the mean $+/-$ SEMs of $n=3-5$ uterine samples/genotype. P-values: **P<0.01, ****P<0.0001. (D-G) Dosage by ELISA of PGE2 (D), PGF2 $\square$ (E) PGI2 (F) and PGD2 (G) in proliferative and secretory WT and L/H-Pgds-/- (KO) uteri ( $n=4$ to 7 for prostaglandin dosage). For PGD2 levels, data are represented as the sum of proliferative and secretory values for WT and KO uteri (G). Prostaglandin levels (mean \pm SEMs) were normalised to tissue weight and expressed in $\mathrm{pg} / \mathrm{mg}$ tissue. 
$170 \times 226 \mathrm{~mm}(600 \times 600 \mathrm{DPI})$ 

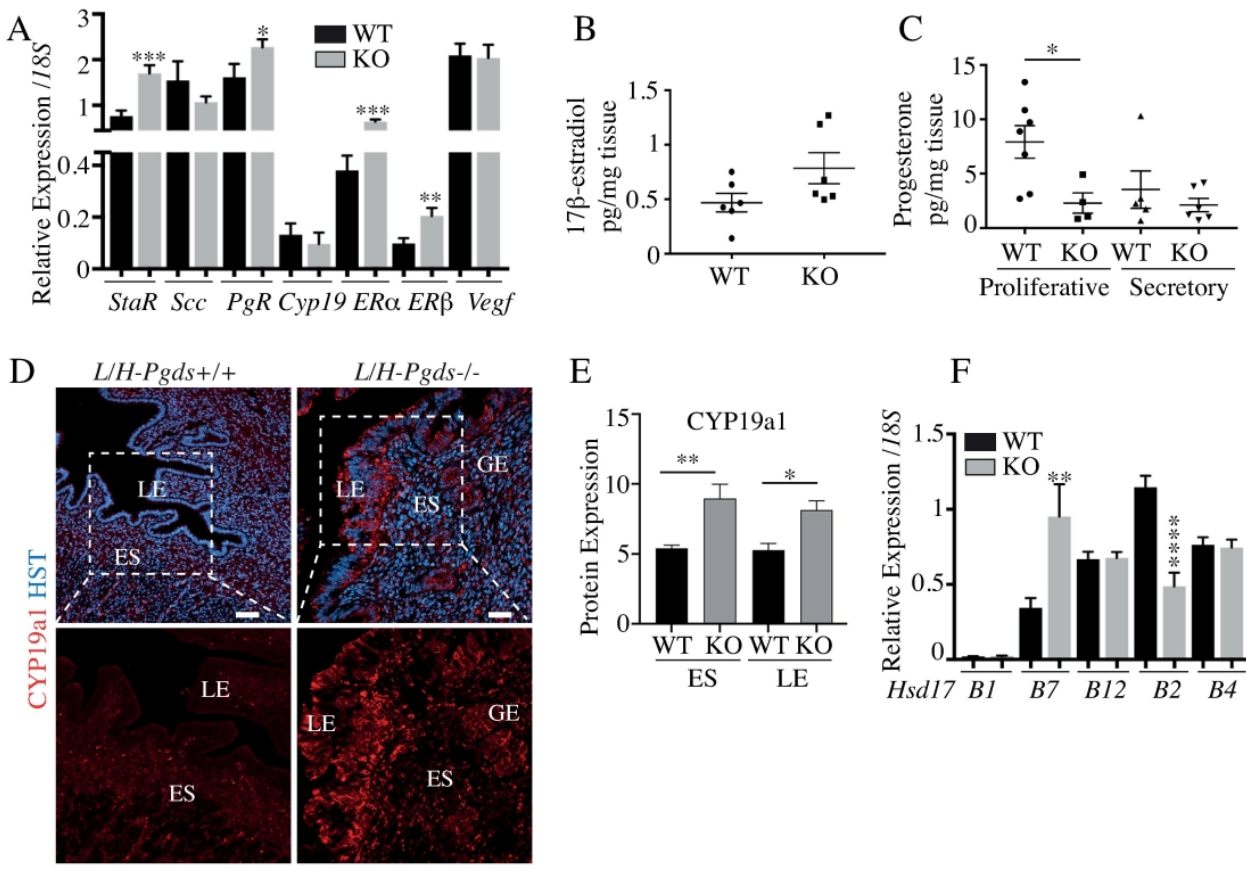

$\mathrm{E}$

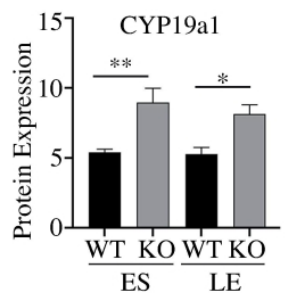

$\mathrm{F}$

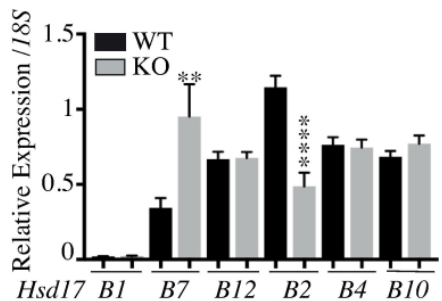

Figure 3

Figure 3 Steroidogenesis is modified in L/H-Pgds-/- uteri. (A) Real time quantitative RT-PCR analysis of steroidogenic gene levels normalised to $18 \mathrm{~S}$ expression in proliferative wild type (WT, in black) and L/HPgds-/- (KO, in grey) uteri. (B-C) 17 $\square$-oestradiol (E2) (B) was quantified in proliferative control (WT) and

L/H-Pgds-/- uteri ( $n=6 /$ genotype) by ELISA and progesterone (C) was quantified in proliferative and secretory control (WT) and L/H-Pgds-/- (KO) uteri ( $n=4$ to 7/genotype) by LC-MS/MS. Steroid levels were normalised to the tissue weight and expressed in $\mathrm{pg} / \mathrm{mg}$ tissue, and represent the mean \pm SEMs. (D) Representative immunofluorescence images of CYP19a1 expression localisation in L/H-Pgds $+/+$ and $\mathrm{L} / \mathrm{H}-$ Pgds-/- uteri in the proliferative phase of the oestrous cycle. Areas in the dashed white squares are enlarged in the lower panels. ES: endometrial stroma; GE: glandular epithelium and LE: luminal epithelium. Scale bar $=150 \square \mathrm{m}$. (E) Quantification of CYP19a1 staining intensity in the endometrial stroma (ES), and luminal epithelium (LE) ( $n=3$ to 4 ROIs for each compartment) of proliferative WT and KO uterus samples. Staining intensities are the mean +/- SEMs of $\mathrm{n}=3-5$ uterine samples/genotype. P-values: $* \mathrm{P}<0.05, * * \mathrm{P}<0.01$. (F) Real time quantitative RT-PCR analysis of Hsd17B gene levels normalised to $18 \mathrm{~S}$ expression in proliferative wild type (WT, in black) and L/H-Pgds-/- (KO, in grey) uteri. (A, F) Relative GPCR expression values are the mean $+/-$ SEMs of 5 samples/genotype. P-values: $* \mathrm{P}<0.05, * * \mathrm{P}<0.01, * * * \mathrm{P}<0.005, * * * * \mathrm{P}<0.0001$. 

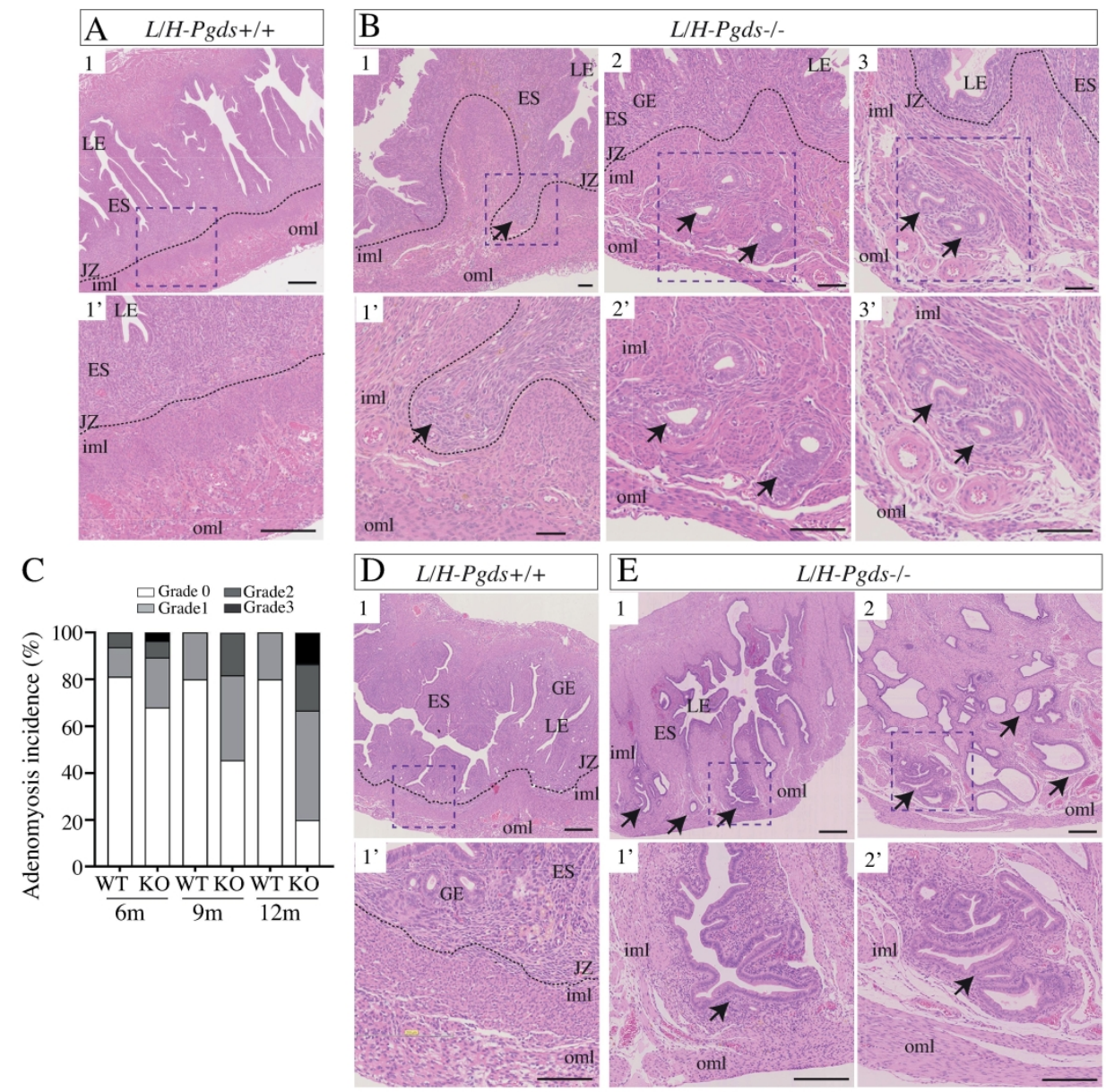

Figure 4

Figure 4 In L/H-Pgds-/- females, lack of PGD2 promotes adenomyosis. (A-B) Representative images of uterus samples from 6-month-old wild type L/H-Pgds+/+ (A) and mutant L/H-Pgds-/- (B) females after haematoxylin-eosin staining. The area within the dashed purple squares in the upper panels $(A 1, B 1-B 3)$ is enlarged in the lower panels ( $\mathrm{A}^{\prime}, \mathrm{B}^{\prime}$ - $\left.\mathrm{B} 3^{\prime}\right)$ to visualise the endometrium/myometrium junction ( $\mathrm{JZ}$, dashed black line) and to highlight adenomyotic lesions (black arrows) in L/H-Pgds-/- uteri (B); Representative lesions are shown, Grade 1 (slight adenomyosis) (B1-B1'); Grade2 (moderate adenomyosis) (B2-B2') and Grade 3 (severe adenomyosis) (B3-B3'). (C) Histogram showing adenomyosis frequency in L/H-Pgds+/+

(WT) and L/H-Pgds-/- (KO) females at the indicated ages (m: months). Adenomyosis frequency was expressed as the percentage of animals without adenomyosis (Grade 0), Grade 1, Grade 2 and Grade 3 lesions relative to all analysed mice. (D-E) Representative images of uterus samples from 12-month-old L/H-Pgds+/+ (D) and L/H-Pgds-/- (E) females after haematoxylin-eosin staining. The dashed black line delineates the $\mathrm{JZ}$ at the endometrium/myometrium junction (D) and the area within dashed purple squares (D1, E1-E2) is enlarged in the lower panels (D1', E1'-E2') to show adenomyotic lesions (black arrows). (A-B, D-E) oml: outer myometrium layer; iml: inner myometrium layer; JZ: junctional zone; ES: endometrial stroma; GE: glandular epithelium and LE: luminal epithelium. Scale bars: $300 \square m$ (A-B 1-3, D-E 1-2) and $150 \square \mathrm{m}\left(\mathrm{A1} 1^{\prime}, \mathrm{B} 1^{\prime}-\mathrm{B} 3^{\prime}, \mathrm{D1} 1^{\prime}, \mathrm{E1} 1^{\prime}-\mathrm{E} 2^{\prime}\right)$. 
$L / H-P g d s+/+$
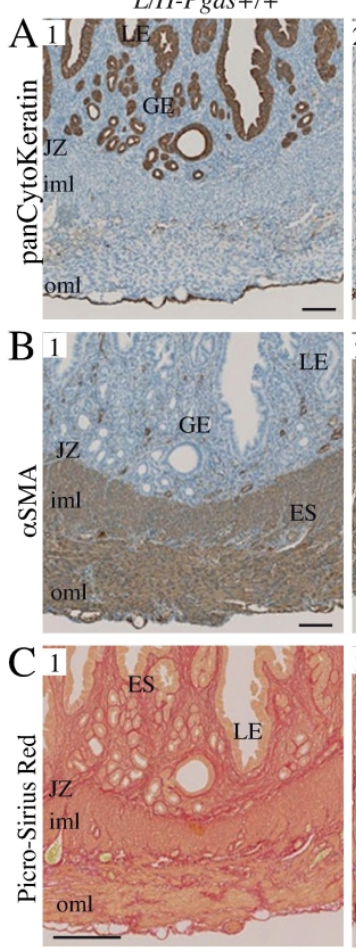

L/H-Pgds-/-
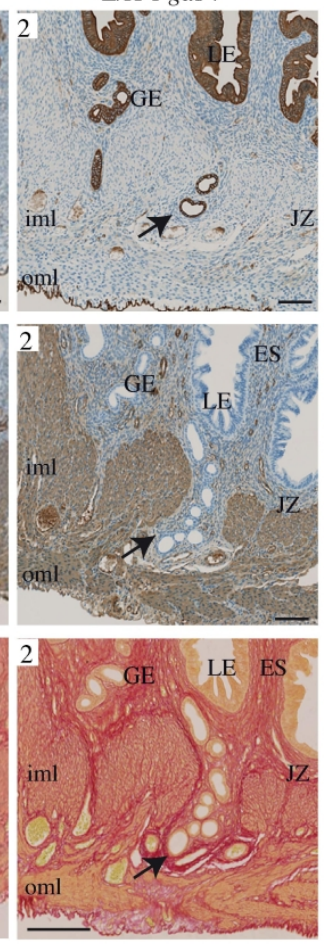

L/H-Pgds-/- Adm
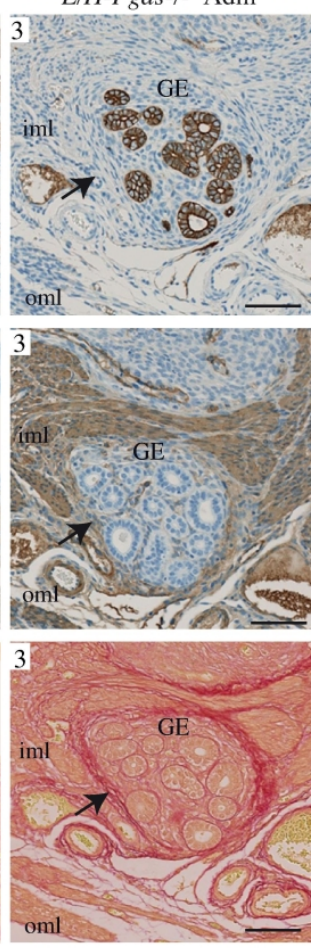

Figure 5

Figure 5 Characterisation of the L/H-Pgds-/- uterus phenotype. (A-B) Representative immunohistochemistry images of pan-cytokeratin (A) and $\square \square$ Sma (B) expression in serial sections in the uterus of 6-month-old $\mathrm{L} / \mathrm{H}-\mathrm{Pgds}+/+$ and $\mathrm{L} / \mathrm{H}-\mathrm{Pgds}-/$ - females at the proliferative stage of the oestrous cycle and in an adenomyotic uterus (L/H-Pgds-/- Adm); (C) Representative images of picro-sirius red staining highlighting collagen fibres in uteri from $\mathrm{L} / \mathrm{H}-\mathrm{Pgds}+/+$ and $\mathrm{L} / \mathrm{H}-\mathrm{Pgds}-/-$ females and in an adenomyotic uterus $(\mathrm{L} / \mathrm{H}-\mathrm{Pgds}-/-\mathrm{Adm})$ at the proliferative stage of the oestrous cycle. Black arrows (A-C) indicate adenomyotic lesions in L/H-Pgds-/uteri. (A-C) Oml: outer myometrium layer; iml: inner myometrium layer; JZ: junctional zone; ES: endometrial stroma; GE: glandular epithelium; LE: Iuminal epithelium. Scale bars: $300 \square m(A-C)$.

$$
173 \times 145 \mathrm{~mm}(600 \times 600 \mathrm{DPI})
$$



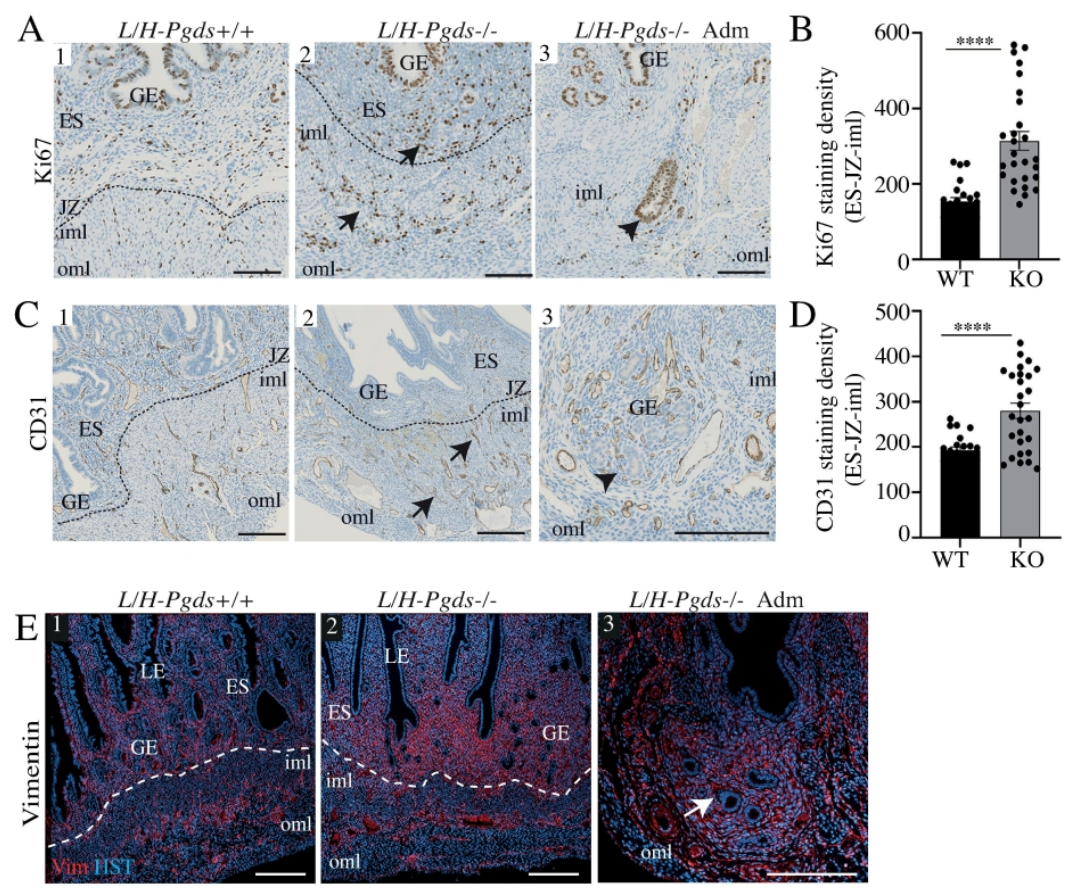

Figure 6

Figure 6 Adenomyosis biomarker identification in L/H-Pgds-/- uteri. Representative immunostaining images of Ki67 (A) and CD31 (C) expression in 6-month-old L/H-Pgds+/+ and L/H-Pgds-/- uteri, and in adenomyotic lesions (L/H-Pgds-/- Adm). Dashed black lines delineate the junctional zone (JZ) between endometrial stroma and myometrium. Black arrows highlight proliferating cells (A) and blood micro-vessels (B); black arrowheads identify adenomyotic lesions. Scale bar= $150 \square \mathrm{m}$. (B, D) Quantification of Ki67 (B) and CD31 (D) staining density in the endometrial stroma (ES)-junctional zone (JZ) and inner myometrium (iml) of L/H-Pgds+/+ (WT) and L/H-Pgds-/- (KO) uteri. Data are shown as the mean +/- SEMs ( $n=3$ to 6 ROIs overlapping the ES-JZ-iml zones) of WT and KO uteri ( $n=5 /$ genotype). P-values: $* * * * P<0.0001$. (E) Representative immunofluorescence images of vimentin expression (in red) in 6-month-old $\mathrm{L} / \mathrm{H}-\mathrm{Pgds}+/+$ and L/H-Pgds-/- uteri, and adenomyotic lesions (L/H-Pgds-/- Adm); nuclei were stained with Hoescht (HST, in blue). Dashed white lines delineate the endometrial stroma/myometrium junction. White arrow identifies an adenomyotic lesion. Oml: outer myometrium layer; iml: inner myometrium layer; ES: endometrial stroma; GE: glandular epithelium and LE: luminal epithelium. Scale bars: $300 \square \mathrm{m}(\mathrm{A}-\mathrm{C})$. 
$158 \times 231 \mathrm{~mm}(600 \times 600 \mathrm{DPI})$ 


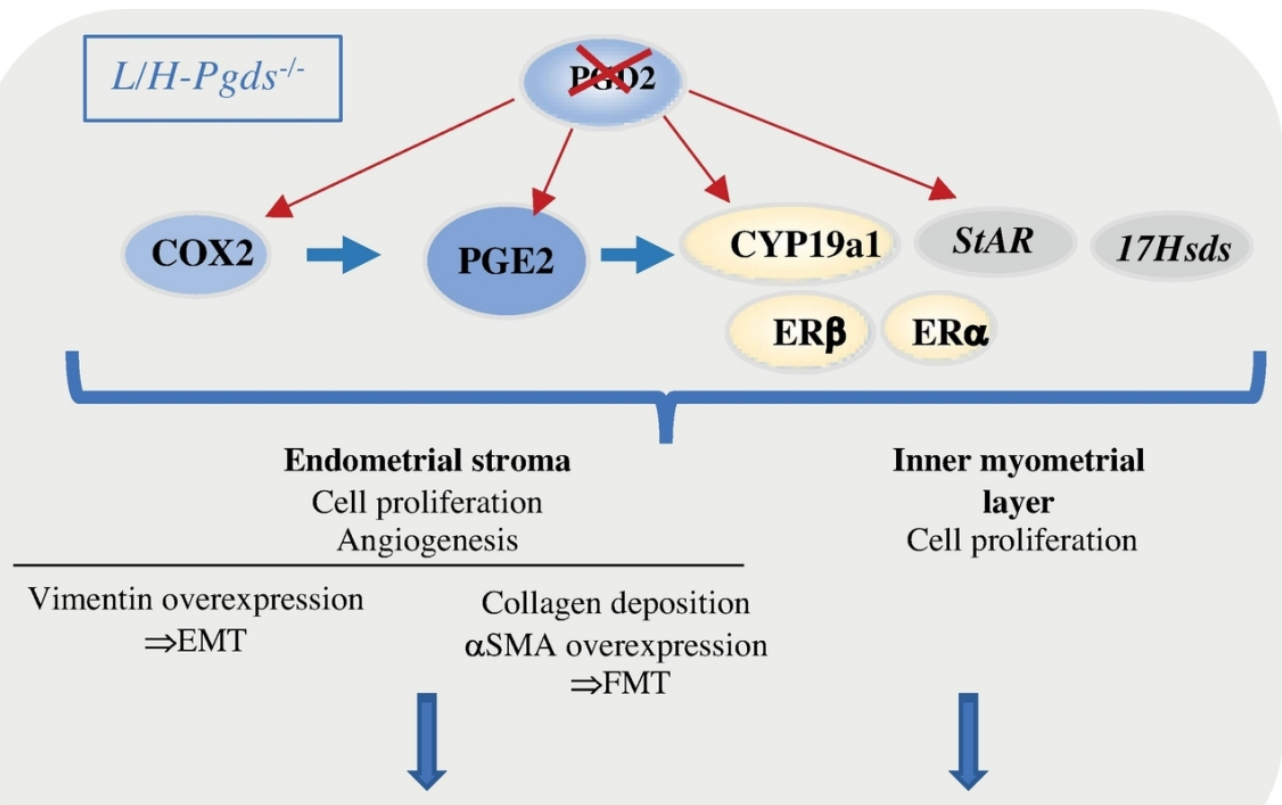

Increased susceptibility to develop Adenomyosis

Figure 7

$109 \times 92 \mathrm{~mm}(300 \times 300 \mathrm{DPI})$ 